\title{
(Im)precisiones de la interpretación conforme constitucional: dimensiones y elementos en la jurisprudencia de la Corte Constitucional colombiana*
}

\author{
Constitutional Conforming Interpretation \\ (In)accuracies: Dimensions and Elements \\ of the Colombian Constitutional Court's \\ Case Law*
}

\begin{abstract}
(Im)precisões da interpretação de acordo com a constituição: dimensões e elementos na jurisprudência do Tribunal Constitucional da Colômbia*
\end{abstract}

\begin{abstract}
Édgar Hernán Fuentes-Contreras**
* Artículo de investigación que expone resultados vinculados al proyecto de investiga- ción posdoctoral del autor en la calidad de becario de la Universidad de los Andes, Chile, bajo la dirección del profesor José Ignacio Martínez Estay. / Research article that presents results related to the author's postdoctoral research project as a fellow of the Universidad de los Andes, Chile, supervised by Professor José Ignacio Martínez Estay. / Artigo de pesquisa em que são expostos os resultados vinculados ao projeto de pesquisa de pós-doutorado do autor como bolsista da Universidad de los Andes, Chile, sob a orientação do professor José Ignacio Martínez Estay.

** https://orcid.org/0000-0002-1066-0999. Investigador de Posdoctorado, Universidad de los Andes, Chile. edgar.fuentes@miuandes.cl; edherfucon@gmail.com
\end{abstract}

Recibido: 21/07/2020. Envío a pares: 15/09/2020 Aprobado por pares: 05/04/2021. Aceptado: 06/07/2021

DOI: 10.5294/dika.2021.30.2.2 


\section{Resumen}

Este texto explora las temáticas relacionadas con la interpretación conforme al interior de las decisiones de la Corte Constitucional colombiana, para así advertir no solo sus diferentes dimensiones, sino sus implicaciones dentro del ordenamiento y su relación con principios, normas y parámetros del control constitucional. De tal forma, en cuatro acápites, previos a las conclusiones, se exponen y correlacionan, primero, el marco conceptual de la interpretación constitucional y sus modalidades; después, la metodología empleada para la recolección de las decisiones del tribunal, para pasar a los resultados obtenidos del análisis de la jurisprudencia, $y$, finalmente, acceder a las reflexiones y propuestas para la discusión sobre las ventajas o limitantes de la categoría objeto de estudio.

\section{Palabras clave}

Constitucionalismo; función judicial; control constitucional; interpretación constitucional; interpretación conforme. 


\section{Abstract}

This article explores topics related to conforming interpretation in the decisions of the Colombian Constitutional Court. For this, it explores not only its different dimensions but also its implications within the legal system and its relationship with the principles, standards, and parameters of constitutional control. The paper is divided into four sections. First, it provides a conceptual framework of constitutional interpretation and its modalities. Then, it describes the methodology used to collect the court decisions. The third section presents the results obtained from the case law analysis. Finally, some reflections and proposals are put forward to discuss the advantages or limitations of the category under study.

\section{Keywords}

Constitutionalism; judicial branch; constitutional control; constitutional interpretation; conforming interpretation. 


\section{Resumo}

Este artigo explora os temas relacionados à interpretação, de acordo com as decisões do Tribunal Constitucional da Colômbia, para alertar não apenas suas diferentes dimensões, mas também suas implicações no sistema jurídico e sua relação com princípios, normas e parâmetros de controle constitucional. Assim, o artigo está dividido em quatro seções: inicialmente são expostos e correlacionados o quadro conceitual da interpretação constitucional e suas modalidades; na segunda seção, é apresentada a metodologia utilizada para coletar as decisões dos tribunais; a terceira expõe os resultados obtidos com a análise da jurisprudência e, finalmente, são mostradas as reflexões e as propostas de discussão sobre as vantagens ou limitações da categoria em estudo.

\section{Palavras-chave}

Constitucionalismo; Função Judicial; Controle constitucional; Interpretação constitucional; Interpretação conforme. 
Sumario: Introducción. 1. Elementos para la comprensión de la interpretación constitucional. 2. Metodología de recolección. 3. Tratamiento de la jurisprudencia constitucional a la interpretación conforme. 3.1 Los conceptos. 3.2 Principios involucrados. 3.3 Normas sujetas a la interpretación conforme. 3.4 Disposiciones exigibles como referente. 4. Reflexiones y propuestas. Conclusiones. Bibliografía.

\section{Introducción}

A pesar de que el instrumento forjador del constitucionalismo colombiano vigente proviene del año 1991, en muchos aspectos sigue siendo un modelo cándido y en constante modificación. Justamente, fenómenos como la indeterminación de los conceptos constitucionales ${ }^{1}$ han llevado a que la facticidad del Estado constitucional haya requerido la inserción de nuevas modalidades de interpretación, no compatibles del todo con los modelos propios de la interpretación legal.

En esa medida es que se ha hecho común ver cómo la Corte Constitucional de Colombia no ha limitado su labor a ser un legislador negativo, en términos kelsenianos, ${ }^{2}$ sino que haya asumido, además, funciones dinámicas y de interacción. ${ }^{3}$ Dichas funciones se han ejecutado, verbigracia, por medio de pronunciamientos modulados como las sentencias interpretativas (condicionadas), sentencias integradoras (aditivas), sentencias sustitutivas y sentencias exhortativas. ${ }^{4}$

En ese marco, el presente artículo ahonda en la figura de la interpretación conforme, la cual, pese a tener un realce como método de armonización del derecho nacional y el derecho internacional, ${ }^{5}$ tiene su construcción, igualmente, en el quehacer constitucional propiamente dicho. Ahora, para tal fin se tendrá como

1 "Así, mediante la introducción de un concepto indeterminado se buscaría que 'sea el juez quien en cada momento lo precise'. Pero como se comprenderá, esta opción supone asumir el riesgo propio de un indeseado activismo judicial, que puede llevar a que los jueces impongan sus propias convicciones personales, en temas en los que justamente no existe consenso, o hay visiones diversas y legítimas, bajo la excusa de su deber de precisar conceptos abiertos" (José Ignacio Martínez Estay, "Los conceptos jurídicos indeterminados en el lenguaje constitucional", en Revista de Derecho Político 105 (2019), pp. 166-167, https://doi.org/10.5944/ rdp.105.2019.25272). Cfr. José Ignacio Martínez Estay, Constitución, conceptos indeterminados y conceptos controvertidos, Valencia, Tirant lo Blanch, 2021.

2 Hans Kelsen, ¿Quién debe ser el defensor de la Constitución?, 2 ed., Madrid, Tecnos, 1999.

3 Édgar Hernán Fuentes-Contreras, “Dinámica y Constitución: ejecución del control constitucional judicial más allá del legislador negativo", en J. M. Tayah, L. D. Romano y P. Aragão (coords.), Reflexiones sobre Derecho Latinoamericano, São Paulo, Livre Expressão, 2013. pp. 277-290.

4 Hernán Alejandro Olano García, “Tipología de nuestras sentencias constitucionales”, en Vniversitas 108 (2004), pp. 571-602. Para su uso en el contexto italiano véase, entre otros, Roberto Romboli, “La interpretación de la ley a la luz de la Constitución. La llamada 'interpretación conforme' en las relaciones entre la Corte Costituzionale y los jueces ordinarios en Italia", en Derecho PUCP 60 (2007), pp. 123-169.

5 Véase, entre otros, Paola Andrea Acosta Alvarado y Julián Eduardo Huertas Cárdenas, “Teorías sobre la relación entre el derecho interno y el derecho internacional en la jurisprudencia constitucional colombiana", en J. I. Acosta López, P. A. Acosta Alvarado y D. R. Ramírez (eds.), De anacronismos y vaticinios. Diagnóstico sobre las relaciones entre el derecho internacional y el derecho interno en Latinoamericana, Bogotá D.C., Universidad de La Sabana, Sladi Lasil y Universidad Externado de Colombia, 2017, pp. 681-704; Paola Andrea Acosta Alvarado, Diálogo judicial y constitucionalismo multinivel. El caso interamericano, Bogotá D.C., Universidad Externado de Colombia, 2014; Paola Andrea Acosta Alvarado, "Zombis vs. Frankenstein: sobre las relaciones entre el derecho internacional y el derecho interno", en Estudios Constitucionales 14 (1) (2016), pp. 15-60. 
punto de partida la siguiente indagación: ¿cuál es el uso implementado en los pronunciamientos de la Corte Constitucional colombiana, entre los años 1992 y 2020, respecto a la interpretación conforme?

Pues bien, para aproximarse a este cuestionamiento se recopiló la jurisprudencia con una metodología censitaria temática-como será explicado en su momento-, para después, con un análisis correlacional, determinar las dimensiones y los elementos que han sido vinculados a la categoría objeto de estudio. En consecuencia, el texto se ha dividido en cuatro secciones, antes de las conclusiones: la primera, expone un recorrido básico sobre las percepciones interpretativas, para después hacer referencia a la metodología adoptada; seguidamente, ordenar los resultados y así pasar al componente reflexivo del artículo.

\section{Elementos para la comprensión de la interpretación constitucional}

El entendimiento del derecho como un fenómeno lingüístico o comunicacio$\mathrm{nal}^{6}$ ha direccionado el hecho de que la norma jurídica no basta con ser creada, sino que, además, requiere ser objeto de asimilación para su correspondiente aplicación. Justo, si se piensa que el precepto normativo tiene un receptor dependiente de la obligación contenida en la regla, ${ }^{7}$ su eficacia dependerá de que el deber sea materializado en la realidad. De allí que el problema de la eficacia jurídica se convierte en un punto central y necesario para concebir de manera completa e íntegra al sistema jurídico.

Con todo, el cómo alcanzar la eficacia está en manos del modo en el que se perciben el rol y la labor interpretativa de los operadores jurídicos. Basta con recordar, por ejemplo, cómo ese rol resultó de carácter pasivo hacia finales del siglo XVIII e inicios del XIX, en el marco de la exégesis francesa, ${ }^{8}$ que es-

6 Véanse, entre otros, Gregorio Robles, Teoría del derecho: fundamentos de teoría comunicacional del derecho, Navarra, Civitas-Thomson y Reuters-Aranzadi, 2015; Gregorio Robles, "El derecho como text. En torno a la fundamentación de una Teoría Comunicacional del Derecho", en Persona y Derecho 35 (1996), pp. 195-226; Juan Pablo Sterling Casas y Pedro María Osma, "La hermenéutica en la Teoría Comunicacional del Derecho: la teoría de textos", en Filosofía UIS 17 (1) (2018), pp. 243-269; María Cruz Díaz De Terán Velasco, "Algunas cuestiones sobre la fundamentación de la Teoría Comunicacional del Derecho", en Derecho \& Sociedad 48 (2017), pp. 113-119.

7 Se hace mención aquí a la diferencia entre obligación primaria y secundaria propuesta por Kelsen: “Una, la que establece el deber jurídico de un sujeto (por ejemplo, no matar); otra, la que establece que debe ser una sanción si se produce una determinada conducta, que es precisamente la contraria a aquella que constituye el deber jurídico (si alguien mata deben ser de diez a quince años de prisión). Si esto es así, la primera norma depende de la segunda y, a la postre, sobra, pues el deber jurídico se deduce ya de la segunda norma. Kelsen llama a esta segunda norma, norma primaria (por razones evidentes), y a la primera norma, norma secundaria" (Íñigo Álvarez Gálvez, "Sobre el concepto de Deber Jurídico de Hans Kelsen”, en Boletín de la Facultad de Derecho 16 (2000), p. 35). Puntualmente, en Hans Kelsen, Teoría general del derecho y del Estado, México D.F., UNAM, trad. Eduardo García Máynez, 1995.

8 “Con la promulgación de los códigos napoleónicos, el nuevo Código Civil francés extrapolaría su estructura y principios al de comercio, germina así en el país galo una nueva forma de comprensión de la ciencia del derecho, la denominada École de l'exégèse. Esta corriente se basó en que la ley debía ser la única fuente posible de derecho, idea influenciada por la división de poderes y otros factores de tipo histórico propios de Francia, como la preponderancia del poder legislativo en la tradición francesa” (Andreu Gálvez, “Una breve aproxi- 
tuvo influenciada por la exégesis teológica9 ${ }^{\text {y }}$ los métodos medievales de las primeras universidades occidentales. ${ }^{10}$

Pese a que la percepción de la exégesis siempre está mediada por la visión alemana orientada por los pensamientos de Friedrich Karl von Savigny, ${ }^{11}$ se ha utilizado una descripción efectuada por Montesquieu, para comprender su posición frente a la actividad judicial: "los jueces de la nación no son, según sabemos, sino la boca por donde habla la ley, seres inanimados que no pueden moderar ni su fuerza ni su rigor". ${ }^{12}$

De este modo, el legislativo sería el encargado de desarrollar una tarea que, inspirada en el interés general, consistiría en vigilar el mantenimiento de la ley y de la autoridad legislativa. Una tarea así no podía encomendarse a la autoridad judicial que se revelaba, precisamente, el objeto de dicha vigilancia, pues se corría el riesgo de que, en el ejercicio de la función que privativamente se les asignaba de solventar los litigios entre particulares, los jueces sustituyesen con su voluntad la del legislador, convirtiéndose así en legisladores. ${ }^{13}$

Esto generó que el legislador contemplara las reglas para la solución de posibles conflictos normativos y herramientas para resolver las aparentes antinomias del sistema reduciendo, en mucho, el nivel creativo del juez. Empero, y si bien esta narrativa suele identificar a un modelo extendido del positivismo jurídico -en términos de Bobbio de positivismo ideológico o legalismo- ${ }^{14}$ realmente no implicó una uniformidad de la comprensión de la ley. Así, la doctrina alemana reconoció la importancia de la interpretación como una operación intelectual que "tiene por objeto el reconocimiento de la ley en su verdad [...]. La interpretación no está restringida, como creen muchos, al caso accidental de obscuridad. Es una imperfección de la ley, y para buscar el remedio es preciso estudiarla en su estado normal". ${ }^{15}$

mación histórica a la escuela de la Exégesis y conclusiones a las que nos ha llevado la codificación", en Ars Iuris 51 (2016), pp. 16-17). "La exégesis representa la forma más acabada de lo que Paolo Grossi ha llamado 'absolutismo jurídico': una concepción monista del derecho asimilado a la ley estatal codificada que habría asegurado al titular del poder político en el siglo XIX el monopolio de la producción jurídica yendo más allá de los poderes de los monarcas absolutos" (Jean-Louis Halpérin, "Exégesis (escuela)", en Revista de Derecho 48 (2017), p. 275).

9 Andrés Botero Bernal, "Matices a la interpretación tradicional de la Exégesis", en Jurídicas 9 (1) (2012), pp. 120-135.

10 Édgar Hernán Fuentes-Contreras y Luz Eliyer Cárdenas Contreras, “Genealogía de la asimilación de lo normativo: análisis del estudio del Derecho en los inicios de las universidades occidentales", en Razón Crítica 3 (2017), pp. 85-110, https://doi.org/10.21789/25007807.1236.

11 António Manuel Hespanha, “Tomando la historia en serio. Los exégetas según ellos mismos”, en FORUM 3 (2012), pp. 13-51.

12 Charles-Louis de Secondat Montesquieu, El Espíritu de las Leyes, Tomo I, Madrid, Librería General de Victoriano Suárez, trad. Siro García Del Mazo, 1906, p. 237.

13 Manuel José Terol Becerra, “Sobre la interpretación de la Constitución y de la Ley en España (1812-1978)”, en Revista del Centro de Estudios Constitucionales 15 (1993), p. 189.

14 Norberto Bobbio, El problema del positivismo jurídico, México D.F., Fontamara, 2012.

15 Friedrich Karl von Savigny, Sistema de Derecho Romano Actual, $2^{\circ}$ edición, Madrid, Centro Editorial de Góngora, 1873, p. 184. Continúa la cita así: “La libertad de la interpretación resulta, sin embargo, negada, cuando el sentido de una ley llega a ser objeto de una nueva disposición legal; pues, fijado este sentido por una ley posterior o por una costumbre constante, deja de ser libre el intérprete, el cual debe aceptar y aplicar la ley tal como ha sido interpretada, aunque estuviera convencido de la falsedad de esta interpretación" (ibid., pp. 184- 
Distante, entonces, de la visión de la exégesis, las proposiciones de Savigny, de cualquier modo, siguen siendo valoradas como una expresión formalista de la ciencia normativa, a la que se opuso Rudolf von Ihering, quien ve que "el Derecho $[\ldots]$ 'no es mero pensamiento, sino fuerza viva'. El Derecho se inserta así en la vida social como un elemento más de su dinámica". ${ }^{16}$

Estas construcciones identifican algunas variaciones sustanciales respecto a la interpretación, que encontraron cabida según las variables que construyen los modelos estatales y las posibilidades contextuales y epistemológicas. Ciertamente, si se habla del Estado de derecho como forma de organización política, sus variables pueden agruparse del modo siguiente:

Figura 1. Elementos de la conformación perceptiva del Estado de derecho ${ }^{17}$

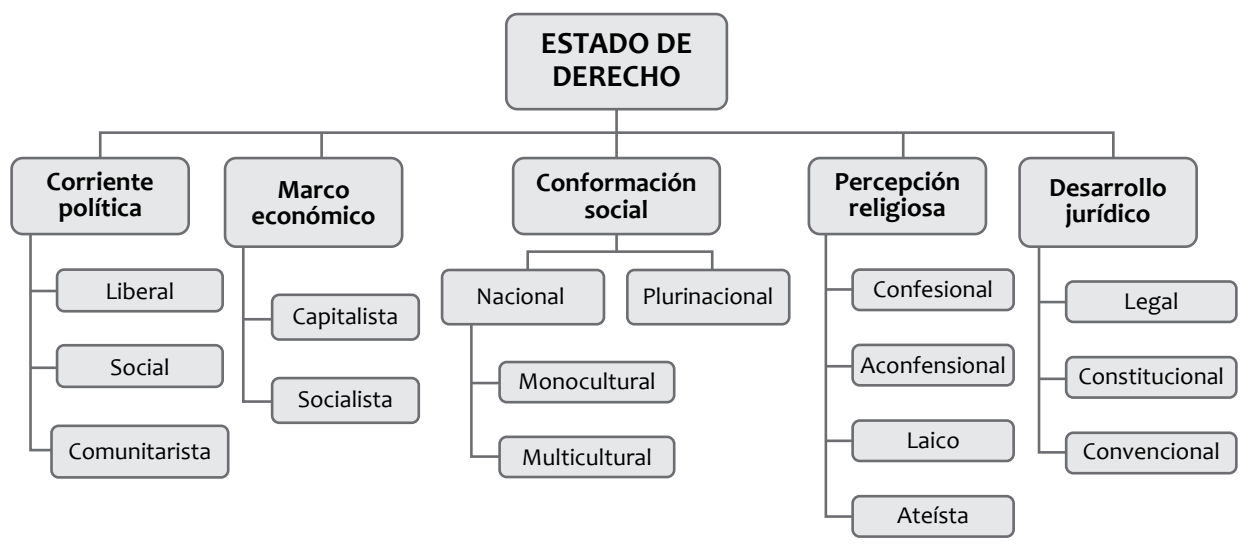

Fuente: elaboración propia.

Centrándose en el desarrollo jurídico, la determinación de la interpretación tiene un vínculo en cuanto a si se está en un Estado legal, constitucional o convencional de derecho, pues un Estado legal supone que la ley es "el peldaño más importante en términos normativos porque la Constitución no tenía una fuerza vinculante inmediata, sino que, se decía, era meramente programática"; ${ }^{18}$

185). "En este sentido es que Savigny distingue cuatro elementos de interpretación. El elemento gramatical, el elemento lógico, el elemento histórico y el elemento sistemático. Dichos elementos no son cuatro clases de interpretación, entre las cuales cada uno pueda escoger según su gusto; son cuatro actividades que deben actuar juntas si la interpretación ha de acertar" (Manuel Barría Paredes, "El elemento de interpretación gramatical. Su origen en Savigny, algunos autores modernos y la doctrina nacional", en Ars Boni et Aequi 2 (2011), pp. 259-260). Dado que comúnmente se alude a los cuatro elementos referenciados por Savigny como métodos de interpretación, se podrá encontrar que, autores como Peter Häberle, incluyan al derecho comparado como "quinto" método de interpretación jurídica (Peter Häberle, "Métodos y principios de interpretación constitucional. Un catálogo de problemas", en Revista de Derecho Constitucional Europeo 13 (2010), pp. 379-414).

16 Felipe González Vicen, "Rudolf von Thering y el problema del método jurídico", en Anuario de filosofía del derecho 4 (1987), p. 248.

$342 \quad 17$ Édgar Hernán Fuentes Contreras, “Del Estado constitucional al Estado convencional de Derecho. Estudio preliminar sobre el modelo del Estado Convencional de Derecho, en el contexto latinoamericano", en Revista Jurídica Digital UANDES 3 (2) (2019), p. 17, http://dx.doi.org/10.24822/rjduandes.0302.2.

18 Francisco J. Laporta, “Materiales para una reflexión sobre racionalidad y crisis de la ley”, en Doxa 22 (1999), p. 321. 
el Estado constitucional ${ }^{19}$ implica una "reivindicación del Poder Constituyente Originario y de los jueces como ejecutores de la garantía e integridad de la Constitución. De tal forma, la justiciabilidad de la obra del Constituyente se vuelve prioridad"; $;{ }^{20}$ mientras que un Estado convencional se advierte por la armonización -que se espera- entre las normas constitucionales y aquellas contempladas por el derecho internacional de los derechos humanos. Así las cosas, si se piensa en los cambios surtidos dentro del Estado consti-
tucional $^{21}$ al concepto propio de la Constitución ${ }^{22}$ y de la ley, ${ }^{23}$ se tiene que:

Si bien la apariencia o "envoltura" de ese pacto se asemeja a una norma fundamental (ley), sus características no permiten que los tradicionales métodos de interpretación funcionen al igual que cuando se aplican en las normas jurídicas. En la práctica, los jueces requieren del concurso de un conjunto de principios que informen la naturaleza especial de una Constitución, aunque también sea considerada como una norma fundamental. En resumen, esas "particularidades" de la Constitución son las siguientes: a diferencia de la ley, que es un concepto abstracto, la Constitución existe y es una realidad concreta. La Constitución no nació para expresar la regularidad de comportamientos individuales como la ley, sino para convertirse un cauce para que la sociedad se conduzca políticamente y en libertad. Finalmente, las constituciones carecen de una estructura normativa similar a las leyes (un supuesto normativo, la subsunción del hecho y una consecuencia); sino que contiene unas disposiciones de carácter autoaplicativo, otras más bien heteroaplicativas, pero todas igualmente vinculantes y de observancia por los jueces. ${ }^{24}$

Las circunstancias expuestas provocan que el juez renuncie a un rol estático, para fungir como garante activo de la integridad del ordenamiento, es decir, es visto como "el principal protector de los derechos fundamentales y, a través de la interpretación de la norma desde la constitución, es creador del Derecho". ${ }^{25}$ Este parámetro puede ser identificado como un desarrollo de la idea de la Constitución viviente -que se opone a la noción de constitución testamento-y, por ello, "asigna al intérprete operador un trabajo más complejo

19 Carlos Hakansson-Nieto, "El efecto ondulatorio de las fuentes en un Estado Constitucional de Derecho", en THEMIS 67 (2015), pp. 39-48, http://revistas.pucp.edu.pe/index.php/themis/article/view/14455.

20 Fuentes Contreras, "Del Estado constitucional al Estado convencional de Derecho, en el contexto latinoamericano", op. cit., p. 22.

21 "En cuanto ideología, lo que caracterizaría al constitucionalismo es poner en primer plano el objetivo de garantizar los derechos fundamentales; no se limita por ello a 'describir los logros del proceso de constitucionalización, sino los valora positivamente y propugna su defensa y ampliación"' (Manuel Atienza, Interpretación constitucional, Bogotá D.C., Universidad Libre, 2016, p. 71).

22 "No es más que una consecuencia de que la Constitución es Derecho, pues es una norma jurídica (en parte), y por sobre todo, porque ella viene a ser una representación de todo aquello que denominamos Derechos, pues es este un instrumento a través del cual se frena al poder. Pero además su juridicidad y directa aplicabilidad se relaciona especialmente con los derechos y libertades fundamentales que garantiza" (José Ignacio Martínez Estay, "El juez y los efectos de la Constitución en el tiempo", en Estudios Constitucionales 1 (1) (2003), p. 723).

23 Sobre el tema, véase, Édgar Hernán Fuentes Contreras, Legislación en sentido material, Bogotá D.C., Grupo Editorial Ibáñez, 2018.

24 Carlos Hakansson Nieto, “Los principios de interpretación y precedentes vinculantes en la jurisprudencia del Tribunal Constitucional peruano. Una aproximación”, en Díkaion 18 (2009), p. 59, https://dikaion.unisabana. edu.co/index.php/dikaion/article/view/1543.

Orlando Parada Vaca, “El juez en el Estado Constitucional”, en Revista Boliviana de Derecho 13 (2012), p. 7. 
de construcción jurídica; por supuesto que no podrá ignorar al texto constitucional, pero tendrá que recurrir a muchos más elementos para elaborar una respuesta interpretativa". ${ }^{26}$ De tal modo, "no constituye interpretación, en el sentido estricto del término, sino más bien actualización, cuando se lleva a la práctica el contenido de las normas constitucionales" ${ }^{27}$

En esa dirección, para el cumplimiento del rol activo y entre los diversos métodos existentes en el proceso de interpretación constitucional, ${ }^{28}$ se pueden destacar los siguientes:

a. La interpretación dinámica o evolutiva expone, en un primer momento, un dilema entre originalismo y no originalismo, ${ }^{29}$ y se decanta por advertir la necesidad de adaptar la Constitución a las realidades y necesidades actuales para garantizar su perdurabilidad.$^{30}$ De allí que pueda generarse lo que ha sido conocido como una mutación constitucional o reformas informales de la Constitución, ${ }^{31}$ que no deberían superar la idea convencional de la Carta. ${ }^{32}$

b. La interpretación sistemática cuenta con dos sentidos: uno amplio y otro estricto. En el primero, se buscan elementos externos a la propia Constitución para su interpretación y determinación; mientras, en el segundo, la interrelación se da solo con normas constitucionales. ${ }^{33}$ Ambas modalidades

26 Carlos Hakansson Nieto, “Los principios de interpretación y precedentes vinculantes en la jurisprudencia del Tribunal Constitucional peruano. Una aproximación”, op. cit., p. 62.

27 Aníbal Quiroga León, “La interpretación constitucional”, en Derecho PUCP 39 (1985), p. 327.

28 Francisco Javier Díaz Revorio, "La interpretación constitucional y la jurisprudencia constitucional", en Quid Iuris 6 (2008), pp. 7-38; Carlos Adolfo Picado Vargas, "Los valores y la interpretación material, sistemática y evolutiva de la Constitución y los Derechos Humanos a la luz del tridimensionalismo jurídico", en Justicia 25 (2014), pp. 124-150.

29 "El originalismo postula que los jueces deben resolver los casos ateniéndose a las disposiciones establecidas en el texto o claramente implícitas en la Constitución escrita. La otra posición va más allá de las referencias anteriores y la interpretación puede basarse en disposiciones que no aparecen dentro del texto constitucional" (Martín Risso Ferrand, "Mutación e interpretación evolutiva de la Constitución", en Estudios Constitucionales 1 (2017), p. 220). En el contexto norteamericano véase, entre otros, Walter Arévalo Ramírez y Luisa Fernanda García López, "La interpretación constitucional y sus métodos en el sistema jurídico norteamericano", en Ius et Praxis 2 (2018), pp. 393-430.

30 “... dado que la Constitución ha de tener una especial pretensión de permanencia y estabilidad. De este modo, resulta la norma fundamental y suprema de un sistema político y social llamada a perdurar en el tiempo. Esta permanencia no sería posible si la interpretación de la misma no se realizase tomando en cuenta la realidad social a la que ha de aplicarse. Por ello, se ha destacado la importancia de una interpretación evolutiva del texto normativo supremo, que lo vaya adecuando a las cambiantes circunstancias sociales, políticas, económicas, sin llegar a tergiversar o ignorar el significado literal de sus preceptos" (Francisco Javier Díaz Revorio, "Interpretación de la Constitución y juez constitucional”, en Ius 37 (2016), p. 19).

31 Richard Albert, "Los métodos de la reforma informal", en Latin American Law Review 3 (2019), pp. $29-47$.

32 Luciano D. Laise, "La distinción entre interpretación y construcción: una visión crítica del originalismo del significado público", en Ius et Praxis 25 (3) (2019), pp. 249-276, http://dx.doi.org/10.4067/S071800122019000300249.

33 Otra perspectiva sobre sentidos de esta interpretación habla de un sentido fuerte y uno débil: “La distinción se fundamenta en el hecho de que a la primera son reconducibles aquellos argumentos que permiten hacer coherente el sistema, que permiten la prevención de las antinomias, de los conflictos entre las normas, asumiendo este aspecto una función fundamental en la atribución, y/o en la preferencia, de un significado, en la corrección en sentido restrictivo o extensivo del significado del texto normativo. A la segunda subespecie (interpretación sistemática en sentido débil), son reconducibles los otros argumentos interpretativos comúnmente considerados sistemáticos (inconstancia terminológica, etc.), ya que, en estos casos, no se prefiere el fin de la coherencia entre las normas, y la atribución de significado se lleva a cabo en función de criterios 
buscan, en esencia, estabilizar una coherencia interna del ordenamiento y del entendimiento de la obra constituyente.

c. La interpretación conforme "a la Constitución (la Verfassungskonforme Auslegung de la doctrina alemana) [se da] cuando se interpreta un texto normativo de manera que se muestre compatible (o conforme) con la Constitución". ${ }^{34}$ Por ende, será un proceso de reconocimiento y selección de interpretaciones compatibles con las normas constitucionales, que favorece el principio in dubio pro legislatoris. Por ello, si "una norma infraconstitucional al examinarse su constitucionalidad puede admitir varias interpretaciones válidamente posibles, de éstas, algunas conducen al reconocimiento de inconstitucionalidad, otras en cambio admiten la constitucionalidad de la norma, el intérprete debe preferir ésta última, a efecto de evitar la expulsión de la norma del sistema jurídico". ${ }^{35}$

Ahora bien, este último tipo de interpretación será el punto central para la revisión y el análisis de la jurisprudencia de la Corte Constitucional colombiana.

\section{Metodología de recolección}

El realce de los tribunales constitucionales ha forjado un interés especial en la jurisprudencia y el precedente que puede generar; son, entonces, una tendencia los estudios de sus percepciones como referentes de la labor judicial. Con todo, uno de los aspectos de importancia para estos análisis es no caer en un sustento de tomar las "sentencias más relevantes" sin explicar un modelo de recolección de las mismas. Por tal motivo, para los resultados aquí expuestos, se ha optado por una recolección a través de la metodología censitaria temática, que permite establecer una muestra no aleatoria en relación con un universo poblacional de 13.523 providencias que incluyen el término interpretación conforme, ${ }^{36}$ halladas mediante la metodología censitaria literal. De manera puntual,

textuales o teleológicos. Además, en estos casos, el 'sistema' al que se hace referencia está dado por el contexto textual de la disposición o por el ámbito disciplinar al que ésta pertenezca" (Vito Velluzzi, "Interpretación Sistemática: ¿Un concepto realmente útil? Consideraciones acerca del sistema jurídico como factor de interpretación", en Doxa I (21) (1998), pp. 81-82).

34 Marina Gascón Abellán, La interpretación constitucional/Constitución de la República de El Salvador 1983/Ley de procedimientos constitucionales, San Salvador, Consejo Nacional de la Judicatura, 2013, p. 26.

35 Pedro Antonio Enríquez Soto, "La interpretación conforme y su impacto en los jueces mexicanos", en J. M. Serna de la Garza (coord.), Contribuciones al Derecho Constitucional, México D.F., UNAM, 2015, p. 296. “Con la expresión interpretación conforme hemos designado una técnica de interpretación por la que se realiza una operación de hacer compatible dos o más normas con una dirección de ajuste específica; es decir, una norma inferior que se interpreta conforme a una jerárquicamente superior" (Gabriela Rodríguez, Alberto Puppo, Raymundo Gama y Jorge Cerdio, Interpretación conforme, México, D.F, SCJN, OACNUDH y CDHDF, 2013, p. 29).

36 La determinación poblacional y de la muestra se realizó el 31 de mayo de 2020 a las 21:41:31 (GMT-5). Resulta relevante establecer que la aplicación del método censitario encuentra variaciones significativas según el buscador que se tome como base. Por ejemplo, el proporcionado por v llex señala 658 providencias que emplean la expresión completa; cifra que resulta de mayor razonabilidad y que da cuenta de que muchas de las providencias que aparecen en el universo poblacional del buscador de la Corte Constitucional carecen de importancia sobre el objeto de estudio; esto debido a que allí se incluyen expresiones aisladas y no 
El método censitario permite establecer una individualización de las providencias de la Corte Constitucional a través de dos subdivisiones o posibilidades metódicas: método censitario lato sensu o temático y método censitario stricto sensu o literal. El primero de los métodos se vincula con una búsqueda directamente temática del concepto o categoría jurídica de interés, es decir, se emplea una preselección de providencias que han sido clasificadas con anterioridad por la propia Corte Constitucional y se hace un rastreo e individualización de estas. Por su parte, el método censitario literal desarrolla la idea de identificar en cuántas oportunidades el término o expresión se utiliza en la totalidad de pronunciamientos que realiza la Corte Constitucional colombiana. ${ }^{37}$

En definitiva, siguiendo dichas metodologías de recolección, dentro de los índices temáticos que postula la Corte Constitucional se detectaron un total de 45 índices afines con la noción objeto de estudio ${ }^{38}$ y un total de 46 providencias - previo descarte de aquellas que se nombraban más de una vez-. ${ }^{39}$

Teniendo, entonces, como referencia el método temático indicado se logra agrupar las providencias como se muestra en la tabla 1.

Tabla 1. Organización anual de las providencias constitucionales recolectadas sobre interpretación conforme ${ }^{40}$

\begin{tabular}{|c|c|c|c|c|c|}
\hline \multicolumn{6}{|c|}{$\begin{array}{l}\text { Providencias recolectadas sobre interpretación conforme en la Corte } \\
\text { constitucional de Colombia }\end{array}$} \\
\hline \multirow{2}{*}{ Año } & \multirow{2}{*}{ Autos } & \multicolumn{3}{|c|}{ Sentencias } & \multirow{2}{*}{ Total } \\
\hline & & $\mathrm{T}$ & SU & C & \\
\hline 1997 & 0 & 1 & 0 & 0 & 1 \\
\hline 1998 & 0 & 0 & 0 & 0 & 0 \\
\hline 1999 & 0 & 1 & 0 & 1 & 2 \\
\hline 2000 & 0 & 1 & 0 & 1 & 2 \\
\hline 2001 & 0 & 2 & 0 & 6 & 8 \\
\hline
\end{tabular}

como un todo -de tal forma en v llex resultan 14051 providencias-. Dicha revisión en el buscador de $\mathrm{v} \mid$ lex se realizó el 05 de abril de 2021 a las 12:16:31 (GMT-5).

37 Édgar Hernán Fuentes Contreras, Beatriz Eugenia Suárez López y Adriana Rincón Villegas, “Facticidad y acción de tutela: presentación preliminar de un estudio empírico de la formulación y efectos de la acción de tutela en el marco colombiano, entre los años 1992-2011", en Civilizar 14 (27) (2014), p. 45. Édgar Hernán Fuentes Contreras, Materialidad de la Constitución, Bogotá D.C., Grupo Editorial Ibáñez, 2010.

38 Los índices podían citar más de un pronunciamiento, pero los mismos podían ser repetidos en otros índices.

39 Esta selección de providencias asegura, a diferencia de una recolección censitaria literal, que el abordaje que efectúa la decisión del tribunal sobre la noción objeto de estudio cuenta con relevancia, es decir, que será, en principio, central en el desarrollo del tribunal y no simplemente nombrado o usado por los intervinientes.

40 Esta identificación muestra que, pese a que el funcionamiento de la Corte Constitucional inicia en 1992, la selección en índices temáticos que adelantó el tribunal -y que sirve de guía para el desarrollo del actual textocarece de referencias a sentencias previas a 1997, lo que, en todo caso, no indica la ausencia de la expresión con anterioridad, sino la relevancia del término según el buscador de la relatoría empleado. Dicha aclaración se hace pertinente debido a que, utilizando el buscador de $\mathrm{v} /$ lex, se encontraron 24 providencias previas a 1997 que hacen uso de la expresión de manera íntegra; sin embargo, no fueron tenidas en cuenta para los resultados de este documento, primero, para mantener la metodología descrita y, segundo, porque su lectura preliminar no surgió un aporte significativo para la disertación. 


\begin{tabular}{|c|c|c|c|c|c|}
\hline \multicolumn{6}{|c|}{$\begin{array}{l}\text { Providencias recolectadas sobre interpretación conforme en la Corte } \\
\text { constitucional de Colombia }\end{array}$} \\
\hline \multirow{2}{*}{ Año } & \multirow{2}{*}{ Autos } & \multicolumn{3}{|c|}{ Sentencias } & \multirow{2}{*}{ Total } \\
\hline & & $\mathbf{T}$ & SU & $\mathrm{C}$ & \\
\hline 2002 & 0 & 0 & 0 & 3 & 3 \\
\hline 2003 & 0 & 3 & 0 & 0 & 3 \\
\hline 2004 & 0 & 1 & 0 & 0 & 1 \\
\hline 2005 & 2 & 2 & 0 & 2 & 6 \\
\hline 2006 & 1 & 0 & 0 & 3 & 4 \\
\hline 2007 & 0 & 1 & 0 & 0 & 1 \\
\hline 2008 & 0 & 0 & 0 & 0 & 0 \\
\hline 2009 & 0 & 2 & 0 & 1 & 3 \\
\hline 2010 & 0 & 0 & 0 & 1 & 1 \\
\hline 2011 & 0 & 1 & 0 & 1 & 2 \\
\hline 2012 & 0 & 0 & 1 & 1 & 2 \\
\hline 2013 & 0 & 1 & 0 & 0 & 1 \\
\hline 2014 & 0 & 0 & 0 & 0 & 0 \\
\hline 2015 & 0 & 0 & 0 & 1 & 1 \\
\hline 2016 & 0 & 0 & 0 & 2 & 2 \\
\hline 2017 & 0 & 1 & 0 & 1 & 2 \\
\hline 2018 & 0 & 0 & 0 & 0 & 0 \\
\hline 2019 & 0 & 0 & 0 & 1 & 1 \\
\hline Total & 3 & 17 & 1 & 25 & 46 \\
\hline
\end{tabular}

Fuente: elaboración propia.

Con base en los parámetros y las aclaraciones relatadas, se produjo la lectura respectiva de los pronunciamientos y la posterior correlación de los usos constitucionales de la categoría de la interpretación conforme, de donde resultan los resultados que serán explicados.

\section{Tratamiento de la jurisprudencia constitucional a la interpretación conforme}

Partiendo del análisis de la jurisprudencia seleccionada, se identifican cuatro grandes asuntos en cuanto a la interpretación conforme: a) la construcción conceptual, b) los principios vinculados, c) las normativas a las cuales se les es exigible, y d) las disposiciones que serán aplicables para la interpretación conforme. 


\subsection{Los conceptos}

Una circunstancia inicial y llamativa sobre la noción de esta categoría es que, dentro de las fuentes abordadas, no existe una univocidad de la expresión, por el contrario, hay por lo menos cuatro sentidos diferentes.

Una de las primeras referencias se supedita a la idea de que es una herramienta o medio de interpretación, es decir, una técnica, la cual tiene como fin la preservación del derecho y la eficacia del mismo. Por esta razón, el juez tendrá la obligación de interpretar una norma como parte del ordenamiento jurídico y acorde a la constitución. Dicha técnica conlleva, por demás, establecer la inaplicación por inconstitucional como una excepción ${ }^{41}$ y suscita que su uso se limite a cuando haya una ruptura real a la presunción de constitucionalidad de la ley. De esta suerte, cuando existe duda sobre la constitucionalidad de la norma se garantiza el principio de in dubio pro legislatoris. ${ }^{42}$

En esa perspectiva, la Corte Constitucional advierte que, en sus controles abstractos, dado que allí no es factible la inaplicación por inconstitucional, deberá preferirse dictar "sentencias modulativas o condicionadas, en el sentido de escoger entre muchas interpretaciones de una norma la que se adecua o acomoda a los preceptos de la Constitución". ${ }^{43} \mathrm{Al}$ punto que señaló dos supuestos en los que considera válidas estas sentencias:

i) Cuando la Corte, al adelantar el juicio de constitucionalidad sobre una disposición normativa o texto legal, encuentra que de ellas se derivan varias interpretaciones de las cuales solo una resulta conforme a la Constitución y, por tal razón, decide mantenerla como parte del ordenamiento jurídico bajo ese entendido, y ii) cuando la Corte decide expulsar la interpretación que es contraria a la Carta, pero manteniendo en el ordenamiento jurídico la disposición cuya constitucionalidad fue cuestionada. ${ }^{44}$

Con ello, el propio tribunal justifica su intervención para presuntamente evitar vacíos, antinomias y posibles aplicaciones que afecten la igualdad, o, incluso, niegue su intervención cuando los órganos encargados de la aplicación hayan fijado el alcance del precepto legal de manera coherente con la Constitución. ${ }^{45}$

$41 \quad$ “El principio de interpretación conforme tiene su origen en la jurisprudencia de la Corte Suprema de los Estados Unidos, particularmente en el voto formulado por el justice Samuel Chase, en el caso

Hylton vs. United States en 1796, quien expresó: 'si la Corte tiene tal poder de declarar la inconstitucionalidad, soy libre de declarar que nunca lo ejerceré si no se trata de un caso muy claro'"' (Pedro Antonio Enríquez Soto, "La interpretación conforme y su impacto en los jueces mexicanos", en Revista Mexicana de Derecho Constitucional 32 (2015), p. 113).

42 Yenny Andrea Celemín Caicedo, “La influencia de la jurisprudencia de la Corte Constitucional en el proceso legislativo en Colombia", en Precedente 11 (2017), pp. 53-82.

43 Corte Constitucional, Sentencia T-397 del 20 de agosto de 1997, M. P. Antonio Barrera Carbonell.

44 Corte Constitucional, Sentencia C-038 del 1 de febrero de 2006, M. P. Humberto Antonio Sierra Porto. Dicha 348 sentencia empleará dos nociones de la interpretación conforme: la de principio y la de técnica o herramienta. En el mismo sentido, Sentencia C-054 de 2016.

45 Así lo hizo respecto el artículo 86 del Código Contencioso Administrativo modificado por el artículo 31 de la Ley 446 de 1998, al resolver una presunta omisión legislativa, con ocasión de que, según el accionante, no 
Por otra parte, con un amplio tratamiento, se ha empleado la noción de la interpretación conforme como un principio constitucional. ${ }^{46}$ Para tal fin, expresa que dicho principio se desprende del artículo 4 de la Constitución Política de Colombia de 1991 (CP), ${ }^{47}$ y se encargaría, ante la multiplicidad de interpretaciones de una norma, de que existan dos deberes diferenciables para los operadores jurídicos: el primero, es una obligación positiva o de hacer que se materializa en la escogencia de aquella interpretación que tenga un mayor grado de adecuación a los preceptos constitucionales; y, el segundo, será una obligación negativa o de no hacer, que involucra el deber de abstenerse de implementar una interpretación abierta y razonablemente contradictoria a la Constitución.

Ello implica varias cosas: primero, que toda interpretación que no sea conforme a la Constitución, debe ser descartada; segundo, que ante dos interpretaciones posibles de una norma, el juez se debe inclinar por aquella que, en forma manifiesta, resulte más adecuada a los mandatos superiores; tercero, que en caso de dos o más interpretaciones que sean, en principio, igualmente constitucionales, el juez, en ejercicio de su autonomía funcional, deberá escoger en forma razonada aquella que considere mejor satisface los dictados del constituyente en el caso concreto. ${ }^{48}$

En el año 2005, expresamente, la Corte extendió la aplicación de este principio a las normas de naturaleza procesal, cuando estudió una tutela interpuesta contra una decisión judicial que declaró desierto el recurso de apelación contra la sentencia penal respectiva. Esta posición, por un lado, desarrolla el principio de la prevalencia del derecho sustancial que aparece constitucionalmente en el artículo $228 \mathrm{CP}$ y, conjuntamente, la visión de la necesidad de tener, en el derecho interno, recursos adecuados, idóneos y efectivos. ${ }^{49}$ Advirtiendo que

... en un Estado de derecho, los procedimientos judiciales o administrativos, según el caso, están concebidos como forma de conciliar el interés del Estado en resolver

se contempló expresamente la posibilidad de incluir, para la acción de reparación directa, los hechos o las omisiones del legislador (Corte Constitucional, Sentencia C-038 del 1 de febrero de 2006, M. P. Humberto Antonio Sierra Porto).

46 En el mismo sentido, véanse las sentencias C273/99, C-867/01, T-982/01, C-878/11, C-1026/01, T-248/03, T-334/03, T-055/05, C-1153/05, C-038/06, C-076/08, C-444/09, SU539/12, C-967/12, T-632/13, C-172/17, C-250/19.

47 "Este principio representa un desarrollo del artículo $4^{\circ}$ de la Constitución, según el cual, la Constitución es norma de normas, y en todo caso de incompatibilidad entre la Constitución y la ley u otra norma jurídica, se aplicarán las disposiciones constitucionales. Así pues, el principio de interpretación conforme encuentra su fundamento en la supremacía y jerarquía normativa máxima de la Constitución Nacional, a partir de cuya premisa se deriva que toda interpretación jurídica debe arrojar un resultado que no solo no debe ser contrario, ni solamente permitido, sino más allá debe estar ajustado a la Constitución Nacional" (Corte Constitucional, Sentencia T-191 del 20 de marzo de 2009, M. P. Luis Ernesto Vargas Silva). Véase, igualmente, Sentencia C-273 de 1999.

48 Corte Constitucional, Sentencia C-1026 del 26 de septiembre de 2001, M. P. Eduardo Montealegre Lynett. Citada también en Sentencia T-248 de 2003.

49 Juana Inés Acosta López y María Carmelina Londoño Lázaro, “El papel de la justicia nacional en la garantía del derecho a un recurso efectivo internacional", en International Law 16 (2010), pp. 81-114. 
los conflictos sociales y los derechos de los asociados; pero, lógicamente, sin que la eficacia de los medios empleados para cumplir el propósito mencionado se alcance sacrificando los derechos fundamentales de las personas. ${ }^{50}$

Ocasionalmente se adoptó, de igual forma, la interpretación conforme como método de interpretación. Dicha dimensión se traza en la comparación con otras metodologías interpretativas. Así, por ejemplo, habla de su diferencia en relación con los métodos de interpretación literal o nominalista, el histórico y el sistemático, y se asume a la interpretación conforme como sinónimo de la interpretación armónica de la Constitución. ${ }^{51} \mathrm{Su}$ fundamento, como cuando se le nombra como principio, está, según la Corte, en el artículo $4 \mathrm{CP}$, al afirmar que "la hermenéutica legal en un sistema constitucional debe estar guiada, ante todo, por el método de interpretación conforme, según el cual las disposiciones jurídicas deben leerse en el sentido que mejor guarde coherencia con lo dispuesto en la Carta Política", 52 que es, para la Corte, una interpretación híbrida que une los caracteres sistemático y finalista. ${ }^{53}$

Esta concepción valió para que, al instante de estudiar la constitucionalidad de los artículos 388, 396, 397, 398, 399, 400, 403, 404 a 409, 417, 418 del Código de Procedimiento Penal, y los artículos 354 a 367 de la Ley 600 de 2000 -vinculados con la detención preventiva-, se admitiera que la adecuación a la Constitución no es exactamente estática. Por esto, la Corte Constitucional acepta que la Carta colombiana de 1991 es una Constitución viviente:

El carácter dinámico de la Constitución, que resulta de su permanente tensión con la realidad, puede conducir a que en determinados casos resulte imperativo que el juez constitucional deba modificar su interpretación de los principios jurídicos para ajustarlos a las necesidades concretas de la vida colectiva -aun cuando no haya habido cambios formales en el texto fundamental-, lo que incide necesariamente en el juicio de constitucionalidad de las normas jurídicas. El concepto de "Constitución viviente" puede significar que en un momento dado, a la luz de los cambios económicos, sociales, políticos, e incluso ideológicos y culturales de una comunidad, no resulte sostenible, a la luz de la Constitución -que es expresión, precisamente, en sus contenidos normativos y valorativos, de esas realidades-, un pronunciamiento que la Corte haya hecho en el pasado, con fundamento en significaciones constitucionales materialmente diferentes a aquellas que ahora deben regir el juicio de Constitucionalidad de una determinada norma. En estos casos, no se puede considerar que el fallo vulnera la cosa juzgada, ya que el nuevo análisis parte de un marco o perspectiva distinta, que en lugar de ser contradictorio conduce a precisar los valores y principios constitucionales y permiten aclarar o complementar el alcance y sentido de una institución jurídica. ${ }^{54}$ 
Así las cosas, se reafirmó el reconocimiento de la función creadora del juez, como ya se venía haciendo incluso desde los primeros años de la Corte. ${ }^{55}$ Por ende,

\begin{abstract}
... esta función creadora del juez en su jurisprudencia se realiza mediante la construcción y ponderación de principios de derecho, que dan sentido a las instituciones jurídicas a partir de su labor de interpretación e integración del ordenamiento positivo. Ello supone un grado de abstracción o de concreción respecto de normas particulares, para darle integridad al conjunto del ordenamiento jurídico y atribuirle al texto de la ley un significado concreto, coherente y útil, permitiendo encausar este ordenamiento hacia la realización de los fines constitucionales. Por tal motivo, la labor del juez no pueda reducirse a una simple atribución mecánica de los postulados generales, impersonales y abstractos consagrados en la ley a casos concretos, pues se estarían desconociendo la complejidad y la singularidad de la realidad social, la cual no puede ser abarcada por completo dentro del ordenamiento positivo. ${ }^{56}$
\end{abstract}

En todo caso, la Corte expresa que dicha labor no es ilimitada, por lo cual no se avalan las vías de hecho en las decisiones judiciales. ${ }^{57}$ De tal forma, "de la Constitución surgen tres restricciones igualmente fuertes: el respeto por la corrección dentro del sistema jurídico y la realización de los principios, derechos y deberes constitucionales; la jurisprudencia de unificación dictada por las altas Cortes y la jurisprudencia de la Corte Constitucional", ${ }^{58}$ lo cual lleva a que la interpretación conforme sea vista como una modalidad integradora del ordenamiento jurídico. ${ }^{59}$

Por consiguiente, se observa que "los jueces están llamados a interpretar la ley en atención a los valores, derechos y libertades definidas por el constituyente, pues el Texto Superior se encuentra en la cúspide de la pirámide normativa" ${ }^{\prime 60}$

Estas aclaraciones llevaron a que la Corte integrara una tercera obligación en relación con la interpretación conforme. En efecto, como se expuso, la Corte venía hablando de una obligación de hacer y otra de no hacer por parte de los operadores jurídicos para resolver de modo ajustado a la interpretación conforme, solo que en 2012 se explicita una tercera obligación que estaría sustentada en el principio de autonomía judicial, al señalar que "ante dos interpretaciones que sean, en principio, igualmente constitucionales, el juez goza de autonomía para aplicar aquella que considere mejor satisface los dictados del constituyente en el caso concreto", ${ }^{61}$ como sucedió cuando conoció

\footnotetext{
Sobre el tema véanse las sentencias T-422/92, T-406/92, C-222-94, C-265/94.

Corte Constitucional, Sentencia C-836 del 9 de agosto de 2001, M. P. Rodrigo Escobar Gil.

Corte Constitucional, Sentencia T-389 del 28 de mayo de 2009, M. P. Humberto Antonio Sierra Porto. Corte Constitucional, Sentencia T-1031 del 27 de septiembre de 2001, M. P. Eduardo Montealegre Lynett.

"Así las cosas, es posible sostener que sólo mediante la aplicación e interpretación consistente y uniforme del ordenamiento jurídico se pueden concretar y hacer efectivos los derechos subjetivos (sean fundamentales o no) previstos en la Constitución y en la ley" (Corte Constitucional, Sentencia T-468 del 5 de junio de 2003, M. P. Rodrigo Escobar Gil).

60 Corte Constitucional, Sentencia SU-539 del 12 de julio de 2012, M. P. Luis Ernesto Vargas Silva.
}

61 Idem. 
los procesos de tutela frente a la sentencia del Consejo de Estado que declaró la nulidad parcial del numeral3, artículo 2 del Acuerdo 345 de 1998 de la Sala Administrativa del Consejo Superior de la Judicatura, que convocaba a concurso de méritos para la conformación del registro de elegibles para el cargo de director de unidad de la Dirección Ejecutiva de Administración Judicial.

Finalmente, aunque en número reducido, se emplea la expresión interpretación conforme para hacer referencia al resultado del proceso interpretativo. Desde luego, la Corte, con el fin de dar una respuesta en los casos examinados, ${ }^{62}$ dirá que realizó un proceso que consigue una interpretación conforme, y llama la atención que su uso no se compagine con los otros ya explorados, sino con el resultado, con la consecuencia de la tarea de interpretación. En tal sentido, incita una cuarta noción de la categoría descrita. ${ }^{63}$

\subsection{Principios involucrados}

En esa identificación jurisprudencial sobre el uso de la interpretación conforme, se percibió que la Corte acude a principios aledaños para completar su deber de adecuación a las disposiciones con rango constitucional. En la figura 2 se presentan dichos principios involucrados.

De esa coadyuvancia planteada existen principios que parecen ser indiscutibles. De hecho, no es novedoso ni tampoco ajeno que se hable del principio de supremacía e integralidad de la Constitución ${ }^{64}$ y que estas superen la propia presunción de legalidad de los actos administrativos. ${ }^{65}$ Ahora, por el contrario, es llamativo que, pese al reconocimiento de la supremacía constitucional, se exija que la conformidad no sea solo a ella en sentido formal. Si bien esto tiene asiento en la idea de bloque de constitucionalidad, la jurisprudencia extiende la adecuación a la totalidad de obligaciones internacionales. Por esto, cita el principio de prevalencia moderada del derecho internacional, incluyendo, para su explicación, la Sentencia C-400 de 1998, donde el ordenamiento jurídico colombiano fue reconocido como un sistema monista moderado. Puntualmente, se enunció:

62 Véanse sentencias tales como C-319 de 2010 y T-020 de 2011. La primera de ellas estudia la demanda de inconstitucionalidad contra el artículo 145 (parcial) de la Ley 201 de 1995, que daba tratamiento sobre la lista de elegibles de la Carrera Administrativa en la Procuraduría General de la Nación y en la Defensoría del Pueblo; y, la segunda, revisó la tutela interpuesta ante el hecho de que el monto de la mesada pensional del accionante fue reducido y no fue reajustado, para presuntamente proteger el capital que garantiza una pensión a largo plazo.

63 "La diferencia entre interpretación como proceso y como resultado puede verse con más claridad con el siguiente esquema, propuesto por Atienza: 1. Enunciado a interpretar: el texto normativo. 2. Enunciado interpretativo: el enunciado por el cual resolvemos el problema interpretativo. 3. Enunciado interpretado: la sustitución en la disposición objeto de interpretación de la expresión que plantea dudas por la expresión en la que se ha resuelto la ambigüedad sintáctica" (José Ángel Fernández Cruz, "La interpretación conforme con la Constitución: una aproximación conceptual", en Ius et Praxis 2 (2016), pp. 153-188).

64 Véanse las sentencias C-967 de 2012 y C-250 de 2019.

65 Corte Constitucional, Sentencia T-397 del 20 de agosto de 1997, M. P. Antonio Barrera Carbonell. 
... las normas internas se deben leer de manera tal que su sentido armonice al máximo, no solo con los preceptos del Estatuto Superior, sino también con las obligaciones internacionales que asisten a Colombia. Así lo dijo esta Corporación en la providencia antecitada, refiriéndose a las normas convencionales: "en virtud del principio pacta sunt servanda, que encuentra amplio sustento en la carta (C.P. art. 9), como ya se ha visto, es deber de los operadores jurídicos aplicar las normas internas distintas de la Constitución de manera que armonicen lo más posible con los compromisos internacionales suscritos que tiene el país". Por este motivo, no son de aceptación las interpretaciones de la ley que, al oponerla a lo dispuesto en las normas internacionales aplicables, pretendan otorgarle un sentido que riñe con los mandatos de la Carta. ${ }^{66}$

Figura 2. Principios coadyuvantes de la interpretación conforme, según la Corte Constitucional colombiana

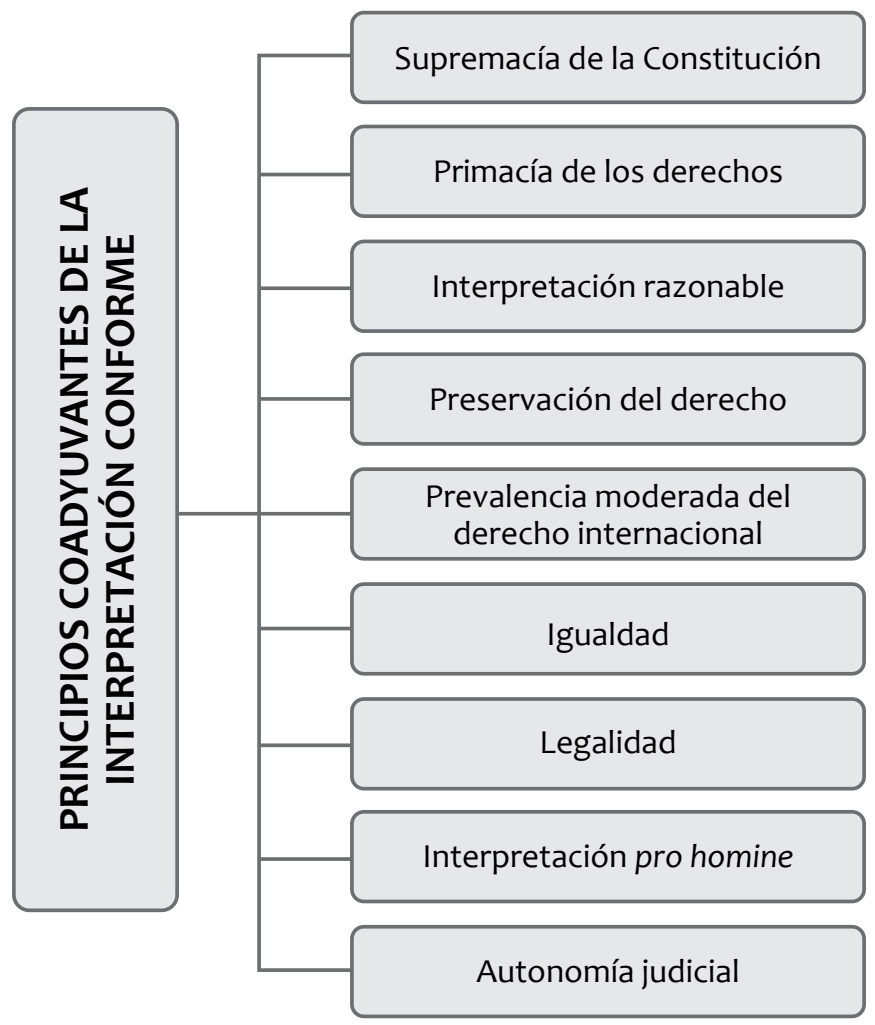

Fuente: elaboración propia.

No obstante la tesis que se sostiene, una lectura precavida da a entender que más que un principio frente a las normas internacionales es una técnica o herramienta de armonización del sistema nacional e internacional, basada en los artículos 9 y 93 constitucional, acompañado de la existencia de leyes aprobatorias de tratados (art. 150.16 CP).

66 Corte Constitucional, Sentencia C-1189 del 13 de septiembre de 2000, M. P. Carlos Gaviria Díaz. 
De igual manera, un principio que secunda abiertamente la interpretación conforme es el de preservación o conservación del derecho. ${ }^{67}$ Según este, "el juez constitucional debe preservar al máximo la labor del Legislador, y por ello debe mantener en el ordenamiento una regulación impugnada, si ésta admite una interpretación conforme a la Constitución" ${ }^{68}$ Por tanto, "el efecto de la interpretación conforme es el de conservar la validez de una ley que, de otra forma, debería ser declarada inconstitucional" ${ }^{69}$ pretendiendo darle eficacia y un efecto útil a las disposiciones que hacen parte del ordenamiento jurídico, al cumplir con requisitos para su existencia-siempre y cuando ese efecto conserve la integridad del sistema jurídico y no sea impropio a la jerarquía normativa-.

Ajustado a los artículos 5 y $228 \mathrm{CP}$, serán citados los principios de primacía de los derechos inalienables de la persona ${ }^{70}$ y de prevalencia del derecho sustancial, ${ }^{71}$ respectivamente. En relación con el artículo 228, la Corte también emplea el principio de autonomía judicial, ${ }^{72}$ que estaría acreditando la potestad del juez de escoger entre dos interpretaciones igualmente constitucionales $\mathrm{y}$, adicionalmente, su capacidad creadora, como se expuso. Esta capacidad, empero, siempre debe respetar el principio de legalidad ${ }^{73}$-entendiéndolo bajo los artículos 230 y $4 \mathrm{CP}$ - y el principio de igualdad ${ }^{74}$ de aquellas personas que acceden a la administración de justicia.

Por último, están dos principios más cercanos a la actividad interpretativa: el de interpretación razonable y el de interpretación pro homine. El primero "supone que el juez debe aplicar las normas de derecho de una manera tal que se produzcan resultados proporcionados, razonables, equitativos y verdaderamente justos, de preferencia sobre el principio jurídico" ${ }^{75}$ Mientras el segundo "impone aquella interpretación de las normas jurídicas que sea más favorable al hombre y sus derechos". ${ }^{76} \mathrm{Al}$ igual que sucede con el tratamiento de la interpretación conforme como principio, la doctrina de adjudicar a un método la categoría de principio se exhibe como inmoderada y promueve una disparidad conceptual que confunde el continente con los contenidos.

En cualquier caso, estos serían los principios que ha enumerado la Corte Constitucional para someter las normas a las cuales se les exige hacer efectiva la interpretación conforme, lo que da paso a revisar dichas disposiciones y su referencia en la doctrina del tribunal.

\footnotetext{
Sentencias T-397/97, C-955/01, C-758/02, C-1153/05, C-038/06, C-054/16, C-172/17.

68 Corte Constitucional, Sentencia C-251 del 11 de abril de 2002, M. P. Eduardo Montealegre Lynett y Clara Inés Vargas Hernández.

69 Corte Constitucional, AUTO A-272 del 13 de diciembre de 2005, M. P. Marco Gerardo Monroy Cabra.

70 Véanse, entre otras, las sentencias C-273 de 1999 y T-982 de 2001.

71 Corte Constitucional, Sentencia T-191 del 20 de marzo de 2009, M. P. Luis Ernesto Vargas Silva.

72 Corte Constitucional, Sentencia SU-539 del 12 de julio de 2012, M. P. Luis Ernesto Vargas Silva.

73 Corte Constitucional, Sentencia C-1026 del 26 de septiembre de 2001, M. P. Eduardo Montealegre Lynett.

74 Corte Constitucional, Sentencia T-355 del 23 de marzo de 2000, M. P. Eduardo Cifuentes Muñoz.

75 Corte Constitucional, Sentencia T-191 del 20 de marzo de 2009, M. P. Luis Ernesto Vargas Silva.
}

76 Idem. 


\subsection{Normas sujetas a la interpretación conforme}

Un discernimiento inicial sobre las normas que estarán sujetas a interpretación conforme, por su vínculo directo con la Constitución y la jerarquía del ordenamiento, son los preceptos de rango legal, sean estos formal o materialmente leyes. ${ }^{77}$ Estas disposiciones se someten a dicha interpretación incluso si han sido dictadas antes de la Constitución de 1991, siempre que cuenten con vigencia. Estos últimos preceptos serían los que con más necesidad pueden requerir la adecuación constitucional debido a que fueron dictados en vigencia de un parámetro diferente al actualmente exigible; situación equivalente sucedería con las leyes proferidas después de 1991, pero previas a reformas constitucionales formales, pues ante su subsistencia no pueden ser incoherentes ni contrarias a las nuevas directrices de cierre.

Ahora bien, como el control constitucional en Colombia puede ser previo, sea por las objeciones presidenciales de inconstitucionalidad a un proyecto de ley $^{78} \mathrm{o}$ de manera automática para los proyectos de leyes estatutarias, ${ }^{79}$ la Corte tuvo oportunidad de afirmar que estos últimos estarán sometidos explícitamente a la interpretación conforme, lo cual se ampliaría analógicamente a los proyectos de ley objetados por el presidente, en atención a que la finalidad última es la preservación del derecho y la propia presunción de constitucionalidad de la actividad legislativa.

Otro tipo de normativa a la cual se hizo mención fueron los actos reformatorios de la Constitución o actos legislativos. Precisamente, en razón de la competencia de la Corte de declarar la inconstitucionalidad de estos por vicios formales (art. 241.1 CP), ${ }^{80}$ el tribunal dijo que, cuando se realiza una reforma a la Constitución, esta, como nueva parte integrante del texto constitucional, debe ser

77 "La interpretación de todas las normas jurídicas de rango legal siempre debe estar acorde con lo dispuesto en el Texto Fundamental. En otras palabras, la hermenéutica legal en un sistema constitucional debe estar guiada, ante todo, por el método de la interpretación conforme, según el cual las disposiciones jurídicas deben leerse en el sentido que mejor guarden coherencia con los fines, valores, principios y derechos expuestos en la Constitución" (Corte Constitucional, Sentencia T-468 del 5 de junio de 2003, M. P. Rodrigo Escobar Gil).

78 Las objeciones se generan como una competencia del Ejecutivo dentro del trámite legislativo, y se pueden presentar una vez ha sido aprobado el proyecto y pasa a la sanción constitucional. Si bien pueden objetarse los proyectos de leyes por inconveniencia o inconstitucionalidad, solo los últimos serán objeto de revisión por la Corte Constitucional (art. 241.8 CP).

79 Este tipo de leyes son concebidas para regular los temas de mayor relevancia constitucional, según el listado taxativo del artículo $152 \mathrm{CP}$.

80 "Se debe resaltar que en la Sentencia C-551 de 2003 se dijo que cuando la Constitución le asigna el control de los vicios de procedimiento en la formación de una reforma constitucional, "no sólo le atribuye el conocimiento de la regularidad del trámite como tal, sino que también le confiere competencia para que examine si el constituyente derivado, al ejercer el poder de reforma, incurrió o no en un vicio de competencia"'. Esta doctrina, que se había establecido en un primer lugar para el control de los referendos constitucionales (art. 376 de la CP), se empezó a implementar también en el control de los actos legislativos del artículo 375 de la CP, en la Sentencia C-1200 de 2003. En dicha jurisprudencia se estableció que el parámetro para hacer el control de los actos reformatorios de la Carta se encuentra en las disposiciones del Título XIII de la Constitución, así como en los preceptos constitucionales y orgánicos pertinentes y en "las normas constitucionales que regulan la competencia en materia de reforma constitucional" (Corte Constitucional, Sentencia C-305 del 25 de abril de 2012, M. P. Juan Carlos Henao Pérez). 
interpretada de conformidad con los preceptos que continúan vigentes de la obra constitucional de 1991. Con todo, pareciese más una obligación de interpretación armónica o sistemática del texto constitucional, que una modalidad de interpretación conforme; esto si se entiende que el uso de dicha interpretación suele estar vinculado a una orientación jerárquica.

Adicional a estas referencias, la Corte incluyó los actos administrativos y los contratos laborales como dependientes de la interpretación conforme. Dicha dependencia ofrece una precisión: no son la generalidad y la abstracción las que obligan a la correspondencia y adecuación con la Constitución, sino su pertenencia al sistema jurídico y su vigencia; esto se armoniza con la afirmación -propia del sistema difuso funcional de control-de que todos los jueces son, en definitiva, jueces constitucionales. Por tanto, el uso de la interpretación conforme no puede ser exclusivo para las normas generales, sino para todas aquellas que puedan ser fundamento para tomar una decisión o para la creación de una norma jurídica.

Este tratamiento comentado se resume en la tabla 2.

Tabla 2. Normas sujetas explícitamente a la interpretación conforme según la Corte Constitucional colombiana.

\begin{tabular}{|c|c|c|}
\hline \multicolumn{3}{|c|}{ Normas sujetas a la interpretación conforme } \\
\hline \multicolumn{2}{|c|}{ Tipo de normativa } & Pronunciamientos \\
\hline \multirow[b]{2}{*}{$\begin{array}{l}\text { Preceptos de } \\
\text { rango legal }\end{array}$} & Anteriores a 1991 & $\begin{array}{l}\text { T-195/99, T-397/97, C-273/99, C-836/01, C-955/01, } \\
\text { T-1031/01, C-426/02, T-334/03, T-216/05, C-076/06, } \\
\text { C-054/16 }\end{array}$ \\
\hline & Posteriores a 1991 & $\begin{array}{l}\text { C-1189/00, C-649-01, C-774/01, C-867/01, C-251/02, } \\
\text { C-758/02, T-248/03, T-907/04, T-055/05, A-207/05, } \\
\text { C-038/06, C-044/06, T-191/09, C-444/09, C-319/10, } \\
\text { T-020/11, C-878/11, C-967/12, SU-539/12 (C-103/15, } \\
\text { C-666/16, C-172/17), }{ }^{82} \text { C-250/19 }\end{array}$ \\
\hline \multicolumn{2}{|c|}{ Proyectos de leyes estatutarias } & C-1153/05 \\
\hline \multicolumn{2}{|c|}{ Actos reformatorios de la Constitución } & C-1040/05 \\
\hline \multicolumn{2}{|c|}{ Actos administrativos } & $\mathrm{T}-397 / 97$ \\
\hline \multicolumn{2}{|c|}{ Contratos de trabajo o ámbito laboral } & T-355/00, T-982/01 \\
\hline
\end{tabular}

$81 \quad$ Hizo alusión a una ley aprobatoria de tratado internacional, la cual tiene control automático posterior (art. 241.10 CP).

82 Los incluidos entre paréntesis se vinculan con decretos leyes, que son aquellos que se producen por delegación legislativa (art. $150.10 \mathrm{CP})$. 


\subsection{Disposiciones exigibles como referente}

Aparte de la codificación de las normas constitucionales en la $\mathrm{CP}$, la Corte Constitucional ha configurado la aplicación de la interpretación conforme a tres normativas adjuntas: a) las demás que conforman el bloque de constitucionalidad, b) los tratados y las normas internacionales, y c) la jurisprudencia de las altas cortes del país.

Para el primer grupo de normas se tiene como referencia que el concepto del bloque de constitucionalidad ha adquirido dos sentidos y que ambos se integran a la Constitución de 1991. Por esto, "se puede decir que la tríada conformada por Constitución-Bloque stricto sensu-Bloque lato sensu puede ser entendida como tres círculos concéntricos" (figura 3): ${ }^{83}$

Figura 3. Distinción de los sentidos del bloque de constitucionalidad en Colombia ${ }^{84}$

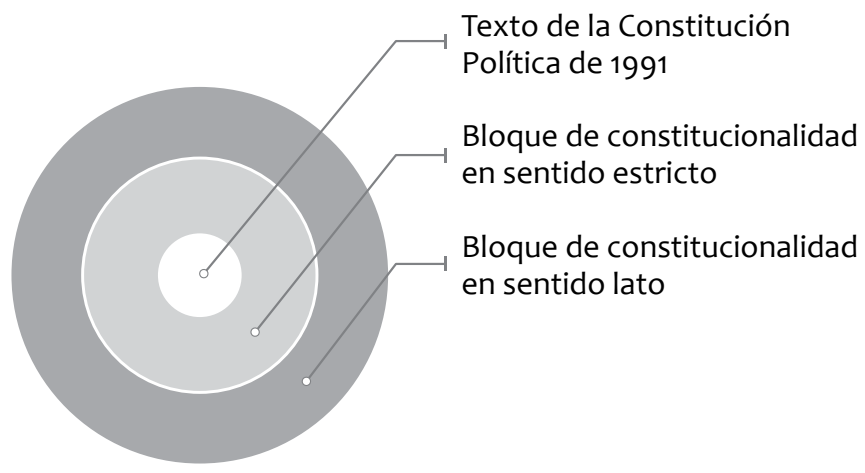

En ese sentido, la diferencia estará en que las normas del bloque de constitucionalidad en sentido estricto (incluyendo, por supuesto, la Constitución) cuentan con rango constitucional, ${ }^{85}$ mientras el bloque en sentido lato podrá incluir normas que, teniendo o no el rango, sirven de parámetro constitucional. ${ }^{86}$ Consecuente con esto, es inevitable afirmar que no será el rango per se, sino su finalidad, lo que marca para que una norma pueda ser tenida en cuenta en una interpretación conforme. ${ }^{87}$ Por consiguiente, desde la doctrina del

83 Édgar Hernán Fuentes Contreras, "Sistema de fuentes colombiano e implementación del Acuerdo de Paz", en Revista Derechos en Acción 5 (2017), p. 95, http://sedici.unlp.edu.ar/handle/10915/64325.

84 Idem.

85 Se han nombrado como integrantes de este sentido del bloque: la Constitución y las normas internacionales que cumplen los requisitos del artículo 93 inciso $1^{\circ} \mathrm{CP}$, es decir que hayan sido aprobadas, traten de derechos humanos y no se puedan suspender en estados de excepción.

86 Estará conformado por las normas del bloque en sentido estricto, algunas leyes estatutarias y orgánicas, leyes que establecen los límites del Estado colombiano y las normas de carácter internacional, según el inciso $2^{\circ}$ del artículo 93 (aprobadas y que traten de derechos humanos) (Fuentes Contreras, Materialidad de la Constitución, op. cit.).

Véanse, entre otras, sentencias C-774 y T-982 de 2001. 
tribunal, deben abarcarse las disposiciones que estarán en el bloque de constitucionalidad en sentido lato.

En lo que respecta a las disposiciones internacionales, la Corte ha usado el concepto del pacta sunt servanda para proyectar el principio de prevalencia moderada del derecho internacional. En manejo de él exhorta a que esta interpretación deba aplicarse y exigirse para que las normas internas se ajusten a las obligaciones adquiridas por el Estado colombiano. En otros términos, "las normas internas se deben leer de manera tal que su sentido armonice al máximo, no sólo con los preceptos del Estatuto Superior, sino también con las obligaciones internacionales que asisten a Colombia", ${ }^{88}$ independientemente de que estas estén por fuera del bloque de constitucionalidad.

Por último, en cuanto el acápite, se han encontrado alusiones respecto al deber de hacer uso de la jurisprudencia y del precedente. ${ }^{89}$ Esta señalización puede ser vista como una correlación práctica entre, por un lado, la competencia con la que cuentan las cortes para unificar y establecer criterios de decisión y, por el otro, la demanda de afianzar el principio de igualdad en los fallos judiciales y el efecto de la cosa juzgada implícita -que es destinado para la llamada ratio decidendi-. ${ }^{90}$ Sin embargo, no por ello es conveniente si se emplea como argumento de autoridad para legitimar una centralización de la tarea interpretativa ${ }^{91} \mathrm{o}$ suplantar la actividad del legislador.

En resumen, sobre la interpretación conforme, ordenando las cuatro temáticas expuestas, ${ }^{92}$ se tendría que:

- Los destinatarios o las personas obligadas frente a los deberes de la interpretación conforme son tanto particulares como agentes del Estado.

- Dichas obligaciones deberán tenerse en cuenta tanto en el momento de crear las disposiciones como en la aplicación e interpretación de los preceptos del ordenamiento jurídico.

- Es obligatoria su aplicación por mandato constitucional e implica que la inaplicación por inconstitucional sea ultima ratio.

88 Corte Constitucional, Sentencia C-1189 del 13 de septiembre de 2000, M. P. Carlos Gaviria Díaz.

89 Primordialmente de aquellos que son creados por los tribunales de cierre. Véanse, entre otras, sentencias T-334 de 2003 y T-216 de 2005.

90 Doctrinalmente véase Hernán Alejandro Olano García, "La cosa juzgada en Colombia”, en Revista Jurídica UCES 11 (2007), pp. 85-95.

91 Virgilio Afonso Da Silva, “La interpretación conforme a la Constitución. Entre la trivialidad y la centralización judicial", en Cuestiones Constitucionales. Revista Mexicana de Derecho Constitucional 1 (12) (2005), pp. 3-28.

92 En el caso mexicano, con presentación equivalente, véase Carlos E. Massé Narváez y Juan Rivera Hernández, "La hermenéutica en la interpretación conforme de los derechos humanos en el orden jurídico mexicano", en Methaodos 2 (1) (2014), pp. 36-44. 
- La adecuación debe hacerse con las normas de rango constitucional, con las que sin tenerlo sirven de parámetro constitucional y con aquellas que incluyan obligaciones internacionales.

- La interpretación conforme no se circunscribe exclusivamente a normas de derecho sustancial, sino también para las que son de derecho procesal.

- Dicha interpretación pretende ser una modalidad de armonización y de integridad tanto del ordenamiento interno como de este con el internacional.

\section{Reflexiones y propuestas}

El ejercicio de la constitucionalización del derecho se ha visto acompañado no solo de un proceso de adecuación de las diferentes normativas que integran el ordenamiento jurídico a las normas constitucionales, sino, al mismo tiempo, de ver a la Constitución como una forma extensiva de regulación de las relaciones políticas, económicas, medioambientales y sociales. Empero, este ejercicio debe distinguir aquello que es posible y aquello que es improbable, para no asumir como constitucionalismo consensual lo que termina por ser impuesto. De modo que la construcción de unos preceptos constitucionales efectivos, en primera instancia, se encuentra mediada por su consonancia y capacidad de determinación del acuerdo fundamental y del desarrollo de la organización política, en sentido histórico. ${ }^{93}$

No obstante, dicho requerimiento no suele ser tan claro en el constitucionalismo latinoamericano actual que se ha venido situando, doctrinalmente, como un constitucionalismo transformador, ${ }^{94}$ que se auxilia, con frecuencia, en el activismo judicial y puede acabar sosteniendo, imperceptiblemente, un constitucionalismo carente de consensos y excesivo.

Ciertamente, la dinámica del constitucionalismo ha llevado a reconocer nuevos modelos de interpretación que incluyen procesos de actualización y determinación en un modelo de Constitución viviente. ${ }^{95}$ Ahora, pese a que estos tipos de interpretaciones no son necesariamente exclusivas del Estado constitucional y han encontrado cabida como forma de armonización entre el derecho interno y el derecho internacional, se han establecido como herramientas

93 Sobre el tema véase, por ejemplo, Antonio Carlos Pereira Menaut, “Un concepto d'orsiano de Constitución: en memoria de Álvaro d'Ors", en Razón Española 137 (2007), pp. 303-320; Antonio Carlos Pereira Menaut, Lecciones de Teoría Constitucional y otros escritos, Santiago de Compostela, Andavira, 2016.

94 Véase, entre otros, Leonardo García Jaramillo, “De la 'constitucionalización' a la 'convencionalización' del ordenamiento jurídico. La contribución del ius constitutionale commune", en Revista Derecho del Estado 36 (2016), pp. 131-166; Leonardo García Jaramillo, “Desafíos de la interamericanización del Derecho: la contribución del Ius Constitutionale Commune", en Revista de Derecho Político 1 (97) (2016), pp. 337-368; Armin von Bogdandy, "Ius Constitutionale Commune en América Latina: una mirada a un constitucionalismo transformador", en Revista Derecho del Estado 34 (2015), pp. 3-50.

95 Domingo García Belaunde, "La interpretación constitucional como problema", en Estudios Políticos (Nueva Época) 86 (1994), pp. 9-37. 
esenciales para la comprensión de la labor de los tribunales constitucionales, tal como ha sucedido en Colombia a partir de la entrada en vigencia de la Constitución de 1991.

Justamente, si se asume que "la interpretación constitucional es determinación, 'concretización' (komkretisierung)", ${ }^{96}$ la interpretación de las normas de superior jerarquía es un proceso creador que necesita métodos, lineamientos y límites coherentes. ${ }^{97}$ Sin embargo, como se vio para el caso colombiano, el método de la interpretación conforme no ha tomado un rumbo único en la jurisprudencia de la Corte Constitucional.

Dicha multiplicidad de caminos ha instituido un proceso de "sobreinterpretación" de la Constitución ${ }^{98} \mathrm{o}$ "sobreconstitucionalización", que es tan riesgoso como la "infraconstitucionalización". Es, de este modo, que puede ser analizada la tipificación de la interpretación conforme como principio: tal como sucede con los principios de interpretación pro homine y de interpretación razonable, dicha nominación hace patente una tendencia de atribuir la categoría de principio o derecho a cualquier contenido jurídico.

Este uso configura que dichas interpretaciones se conviertan en mandatos de optimización u optimizables, por tanto, que su empleo sea conducido por una relativización sometida al caso concreto, y se observen como estructuras graduales y carentes de un carácter prima facie. En esta medida, si bien los métodos interpretativos pueden conducir a diferentes resultados, no por ello pueden ser catalogados como principios y menos que puedan llegar a ser un objeto de ponderación.

Lo anterior se deriva, sin duda, de que el uso de las dimensiones de la interpretación conforme en las decisiones de la Corte Constitucional parte de una presunta notoriedad y no de sus diferencias prácticas. Precisamente, si se concibe, por ejemplo, a la metodología como un conjunto de procedimientos racionales o pasos que son utilizados para alcanzar un objetivo o fin, que, además, involucra conocimientos previos, elementos y medios, se puede asegurar que la doctrina constitucional sobre la interpretación conforme como metodología

96 Quiroga León, “La interpretación constitucional”, op. cit., p. 332.

97 “Con frecuencia encontramos en la doctrina jurídica una idea según la cual se debe reconocer a priori la existencia de ciertos principios considerados peculiares o exclusivos de la interpretación constitucional. Cuando se trata de enunciar tales principios, generalmente se mencionan los siguientes: de unidad de la constitución, de armonización u optimización, de interpretación conforme a la constitución; de funcionalidad, de eficacia o efectividad; de favor libertatis, de continuidad de la jurisprudencia, de presunción de legitimidad de las leyes, de prudencia; fundamentalidad, limitación, responsabilidad, control, razonabilidad, perdurabilidad, etc." (Juan Carlos Moncada Zapata, "Principios para la interpretación de la Constitución en la jurisprudencia de la Corte Constitucional colombiana", en Derecho PUCP 53 (2000), p. 133).

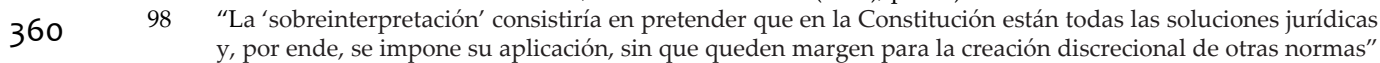
(Rodolfo L. Vigo, La interpretación (argumentación) jurídica en el Estado de Derecho Constitucional, Ciudad de México, Tirant Lo Blanch, 2017, p. 293). 
no ha respetado dicha noción con nitidez -como sí pasa, en cambio, con la proporcionalidad-. No obstante, su uso y los aportes recopilados asienten la siguiente propuesta metodológica para la comprensión de esta interpretación como metodología (tabla 3):

Tabla 3. Elementos metodológicos de la interpretación conforme

\begin{tabular}{|c|c|c|c|c|}
\hline \multicolumn{5}{|c|}{ Interpretación conforme como metodología } \\
\hline 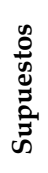 & \multicolumn{2}{|c|}{$\begin{array}{l}\text { Supremacía de la Constitución } \\
\text { Autonomía judicial } \\
\text { Jerarquía normativa }\end{array}$} & $\begin{array}{l}\text { a. Garantía del principio de preservación } \\
\text { del derecho, de efectividad y del principio } \\
\text { pro persona. } \\
\text { b. Conservación de la coherencia del } \\
\text { sistema normativo. }\end{array}$ & 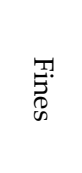 \\
\hline \multirow{6}{*}{ ஜ } & Identificación & \multicolumn{3}{|c|}{$\begin{array}{c}\text { Implica la distinción de los preceptos directamente aplicables para } \\
\text { la solución del caso concreto, su vigencia y su ubicación dentro del } \\
\text { ordenamiento jurídico. }\end{array}$} \\
\hline & Determinación & \multicolumn{3}{|c|}{$\begin{array}{c}\text { Se relaciona con establecer los sentidos posibles de las disposiciones que } \\
\text { estarán en juego para la solución. }\end{array}$} \\
\hline & Adecuación & \multicolumn{3}{|c|}{$\begin{array}{l}\text { Permite la revisión de los sentidos determinados y que los mismos } \\
\text { puedan ser considerados como acordes a los parámetros del sistema. }\end{array}$} \\
\hline & Selección & \multicolumn{3}{|c|}{$\begin{array}{l}\text { De los sentidos adecuados (previo descarte de aquellos que no son } \\
\text { coherentes con las normas parámetro); el operador tendrá la labor de } \\
\text { optar por aquellos que den solución directa del caso. }\end{array}$} \\
\hline & Verificación & \multicolumn{3}{|c|}{$\begin{array}{c}\text { Proceso donde se valora cuál de los sentidos optados y conformes a los } \\
\text { parámetros cumplen de mejor medida los fines previstos sin caer en una } \\
\text { vía de hecho. }\end{array}$} \\
\hline & Decisión & \multicolumn{3}{|c|}{ Involucra la aplicación final del sentido que fue comprometido. } \\
\hline 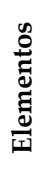 & \multicolumn{2}{|c|}{$\begin{array}{l}\text { Fuentes del derecho (principales } \\
\text { y subsidiarias). } \\
\text { Criterios auxiliares de la decisión } \\
\text { judicial. }\end{array}$} & $\begin{array}{l}\text { Interpretación nominal. } \\
\text { Interpretación sistemática. } \\
\text { Interpretación histórica. } \\
\text { Interpretación finalista. } \\
\text { Proporcionalidad }\end{array}$ & 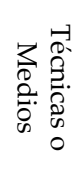 \\
\hline
\end{tabular}

Ahora bien, en materia de la integración con otros principios, se contempla que esta relación se clasifica por la función que ostentan dichos principios en jerarquía, funcionamiento e interpretación:

- En los primeros, es decir, los de jerarquía o prevalencia, estarán: a) supremacía e integridad de la Constitución, b) prevalencia moderada del derecho internacional, c) primacía de los derechos, d) prevalencia del derecho sustancial sobre el procesal.

- En los de funcionamiento se encuentran: a) preservación del derecho, b) igualdad, c) legalidad y d) autonomía judicial. 
- En el tercer grupo están: a) interpretación razonable y b) interpretación pro homine ${ }^{99}$ Resaltando, sin embargo, que estos realmente no deberían ser catalogados como principios.

Empero, el detalle de los principios empleados puede llevar a deducir que la interpretación conforme como método o técnica es el reflejo, en esencia, de la aplicación de la supremacía constitucional y del fin de preservar la integridad del sistema, mediante el reconocimiento de la duda en favor del legislador, por la existencia de una presunción de constitucionalidad de las leyes.

En correspondencia, la normativa involucrada con la interpretación conforme, tanto por pasiva (aquella a la cual se le exige) como por activa (aquella que funge como parámetro), funciona a niveles de jerarquía, especialmente, y con el modelo conocido como norma interpuesta. En ese sentido, frente a los actos reformatorios de la Constitución, al integrarse como normas constitucionales, más allá de estar sometidos a una interpretación conforme, lo estarían a una modulación sistemática y a un deber de interpretación armónica.

A la vez, esto lleva a hacer una crítica a la posición de la Corte de reconocer a la jurisprudencia como parámetro, debido a que, si bien no se avala una autonomía plena en la labor judicial ni que el precedente carezca de sentido vinculante, las decisiones judiciales en el sistema de fuentes fungen como un criterio auxiliar, según el artículo $230 \mathrm{CP}$. De hecho, esa modificación fáctica del rol de la jurisprudencia puede llegar a poner en peligro la naturaleza de la función jurisdiccional, como se ha presenciado, verbigracia, en las sentencias aditivas. ${ }^{100}$ Dicho riesgo se genera por una usurpación de funciones, porque, como bien lo advierte el profesor Pereira Menaut, "la interpretación constitucional debería corresponder al pueblo, y, como ello no es posible, a los órganos políticos menos alejados del pueblo, y nunca debería investirse en una sola institución", ${ }^{101}$ so pena de que el ejercicio de interpretación constitucional termine soportado una presunción de elitismo epistemológico de los jueces: solo "útil" en la medida que se acepten y vean como positivas las decisiones, pero, en todo caso, ajeno a un equilibrio institucional.

99 Estos principios, no entendidos como principios de interpretación, sino en estricto sentido, encuentran contenido en el ordenamiento así: a) el principio pro homine o pro persona, en los artículos 1, 2 y $5 \mathrm{CP}$, al incluir "el respeto de la dignidad humana", el fin de "garantizar la efectividad de los principios, derechos y deberes consagrados en la Constitución" y la "primacía de los derechos inalienables de la persona", respectivamente; y para b) el principio de interpretación razonable o la ponderación, este se ordena en reconocimiento jurisprudencial.

100 "Los jueces deben desempeñar una función catalizadora y deben actuar de forma no invasiva. Antes bien, deben hacer visibles desde el punto de vista jurídico y político problemas sociales soslayados y deben crear incentivos para que las autoridades políticas persigan el bien común y protejan los derechos fundamentales" 362 (Carlos Bernal Pulido, "Fundamentos bíblicos de la separación de poderes y función catalizadora del juez", en Díkaion 28 (2) (2019), p. 243, https://doi.org/10.5294/dika.2019.28.2.1).

101 Antonio Carlos Pereira Menaut, “Un concepto orsiano de Constitución”, en Revista de Derecho 2 (26) (2005), p. 325. 
De manera simultánea, aceptar la jurisprudencia como parámetro de correspondencia supone un aliento hacia el poder moralizante del derecho constitucional, desde el intérprete judicial, mientras se provoca un traspié al Estado democrático, que tiene uno de sus sustentos en la pretensión de que, al final, "la interpretación constitucional debe alejarse de los deseos del que la interpreta en cada momento", ${ }^{102}$ para que se acerque a un reflejo firme de lo fundamental.

Son estos niveles de dispersión, tanto en el uso como en la comprensión del concepto de la interpretación conforme, por ejemplo, lo que impide la articulación esperada dentro de un ordenamiento constitucional y que, a su vez, tergiversa la función jurisdiccional en sus efectos, fines y el objeto mismo de someterse al imperio de la normativa, lo que abre mayores niveles de discrecionalidad en un activismo judicial que, por la naturaleza del órgano mismo, más que una construcción consensuada, puede auxiliar un constitucionalismo impuesto desde lo judicial, que expande el derecho a cualquier ámbito, sin distancia entre las esferas de lo público, lo social y lo privado. Lo anterior hace evidente que la multivocidad, como recurso, lleva a lo equívoco y a estándares imprecisos que no logran proteger, en últimas, la iusfundamentalidad de la igualdad, como elemento no contingente del Estado de derecho.

\section{Conclusiones}

Este artículo expuso dos asuntos principales: por una parte, un diagnóstico y, por la otra, una propuesta crítica. De esta manera, exhibe un análisis que enfatiza en la trascendencia de la interpretación de la obra constituyente como diálogo para la experiencia constitucional y la efectividad de los preceptos de superior jerarquía. Por consiguiente, existen tres conclusiones fundamentales del trabajo realizado.

El acercamiento a la jurisprudencia de la Corte Constitucional muestra un afianzamiento de la categoría de la interpretación conforme. Sin embargo, es carente de univocidad. La Corte no ha utilizado la categoría con un solo y único significado: ha pasado de herramienta a metodología, resultado y principio, lo que ha llevado a que la multiplicidad de usos afecte no solo los niveles de precisión, sino una aplicación clara de los restantes operadores jurídicos.

Dicha situación construye, al vincular la jurisprudencia como parámetro de la interpretación conforme, una superioridad de la función judicial, es decir, un traspaso de la interpretación auténtica de la ley a la jurisdicción, y una modificación, injustificada, del sistema de fuentes constitucionalmente establecido.

102 Juan Manuel Goig Martínez, “La interpretación constitucional y las sentencias del Tribunal Constitucional. De la interpretación evolutiva a la mutación constitucional", en Revista de Derecho UNED 12 (2013), pp. 289. 
En definitiva, la interpretación conforme debería ser tomada como una metodología -no como principio- para que sirva de garantía al constitucionalismo democrático, donde el juez, en sus decisiones, se inserte en una ingeniería constitucional equilibrada y consensuada, para que la Constitución viviente sea, más que un instrumento retórico, un ejercicio del quehacer político de la comunidad.

\section{Referencias}

Acosta Alvarado, Paola Andrea, Diálogo judicial y constitucionalismo multinivel. El caso interamericano, Bogotá D.C., Universidad Externado de Colombia, 2014.

Acosta Alvarado, Paola Andrea, "Zombis vs. Frankenstein: sobre las relaciones entre el derecho internacional y el derecho interno", en Estudios Constitucionales 14 (1) (2016), pp. 15-60. DOI: https://doi.org/10.4067/S071852002016000100002

Acosta Alvarado, Paola Andrea y Julián Eduardo Huertas Cárdenas, “Teorías sobre la relación entre el derecho interno y el derecho internacional en la jurisprudencia constitucional colombiana", en J. I. Acosta López, P. A. Acosta Alvarado y D. Rivas Ramírez (eds.), De anacronismos y vaticinios. Diagnóstico sobre las relaciones entre el derecho internacional y el derecho interno en Latinoamericana, Bogotá D.C., Universidad de La Sabana, Sladi Lasil y Universidad Externado de Colombia, 2017, pp. 681-704. DOI: https://doi.org/10.2307/j.ctv18msn8p.28

Acosta-López, Juana Inés y María Carmelina Londoño-Lázaro, “El papel de la justicia nacional en la garantía del derecho a un recurso efectivo internacional", en International Law 16 (2010), pp. 81-114.

Afonso Da Silva, Virgilio, “La interpretación conforme a la Constitución. Entre la trivialidad y la centralización judicial", en Cuestiones Constitucionales. Revista Mexicana de Derecho Constitucional 1 (12) (2005), pp. 3-28. DOI: https://doi.org/10.22201/iij.24484881e.2005.12.5723

Albert, Richard, "Los métodos de la reforma informal", en Latin American Law Review 3 (2019), pp. 29-47. DOI: https://doi.org/10.29263/lar03.2019.02

Álvarez Gálvez, Íñigo, “Sobre el concepto de Deber Jurídico de Hans Kelsen”, en Boletín de la Facultad de Derecho 16 (2000), pp. 15-57.

Andreu Gálvez, Manuel, “Una breve aproximación histórica a la escuela de la Exégesis y conclusiones a las que nos ha llevado la codificación", en Ars Iuris 51 (2016), pp. 9-22.

364 Arévalo Ramírez, Walter y Luisa Fernanda García López, “La interpretación constitucional y sus métodos en el sistema jurídico norteamericano", en 
Ius et Praxis 2 (2018), pp. 393-430. DOI: https://doi.org/10.4067/S071800122018000200393

Atienza, Manuel, Interpretación constitucional, Bogotá D.C., Universidad Libre, 2016. DOI: https://doi.org/10.18041/978-958-5466-16-6

Barría Paredes, Manuel, “El elemento de interpretación gramatical. Su origen en Savigny, algunos autores modernos y la doctrina nacional", en Ars Boni et Aequi 2 (2011), pp. 257-279.

Bernal-Pulido, Carlos, "Fundamentos bíblicos de la separación de poderes y función catalizadora del juez", en Díkaion 28 (2) (2019), pp. 222-246. DOI: https://doi.org/10.5294/dika.2019.28.2.1

Bobbio, Norberto, El problema del positivismo jurídico, México D.F., Fontamara, 2012.

Bogdandy, Armin von, "Ius Constitutionale Commune en América Latina: una mirada a un constitucionalismo transformador", en Revista Derecho del Estado 34 (2015), pp. 3-50. DOI: https://doi.org/10.18601/01229893.n34.01

Botero-Bernal, Andrés, "Matices a la interpretación tradicional de la Exégesis", en Jurídicas 9 (1) (2012), pp. 120-135.

Celemín Caicedo, Yenny Andrea, "La influencia de la jurisprudencia de la Corte Constitucional en el proceso legislativo en Colombia", en Precedente 11 (2017), pp. 53-82. DOI: https://doi.org/10.18046/prec.v11.2481

Díaz De Terán Velasco, María Cruz, "Algunas cuestiones sobre la fundamentación de la Teoría comunicacional del Derecho", en Derecho \& Sociedad 48 (2017), pp. 113-119.

Díaz Revorio, Francisco Javier, “Interpretación de la Constitución y juez constitucional", en Ius 37 (2016), pp. 9-31. DOI: https://doi.org/10.35487/rius. v10i37.2016.7

Díaz Revorio, Francisco Javier, “La interpretación constitucional y la jurisprudencia constitucional", en Quid Iuris 6 (2008), pp. 7-38. DOI: https://doi. org/10.4067/S0718-52002009000200004

Enríquez Soto, Pedro Antonio, "La interpretación conforme y su impacto en los jueces mexicanos", en J. M. Serna de la Garza (coord.), Contribuciones al Derecho Constitucional, México D.F., UNAM, 2015, pp. 289-326. DOI: https:// doi.org/10.1016/j.rmdc.2016.03.004

Enríquez Soto, Pedro Antonio, “La interpretación conforme y su impacto en los jueces mexicanos", en Revista Mexicana de Derecho Constitucional 32 (2015), pp. 111-139. DOI: https://doi.org/10.1016/j.rmdc.2016.03.004 
Fernández Cruz, José Ángel, “La interpretación conforme con la Constitución: una aproximación conceptual", en Ius et Praxis 2 (2016), pp. 153-188. DOI: https://doi.org/10.4067/S0718-00122016000200006

Fuentes Contreras, Édgar Hernán, “Del Estado constitucional al Estado convencional de Derecho. Estudio preliminar sobre el modelo del Estado Convencional de Derecho, en el contexto latinoamericano", en Revista Jurídica Digital UANDES 3 (2) (2019), pp. 13-42. DOI: https://doi.org/10.24822/rjduandes.0302.2

Fuentes Contreras, Édgar Hernán, “Dinámica y Constitución: ejecución del control constitucional judicial más allá del legislador negativo", en J. M. Tayah, L. D. Romano y P. Aragão (coords.), Reflexiones sobre Derecho Latinoamericano, São Paulo-Rio de Janeiro-Buenos Aires, Livre Expressão, 2013, pp. 277-290.

Fuentes Contreras, Édgar Hernán, “Sistema de fuentes colombiano e implementación del Acuerdo de Paz", en Revista Derechos en Acción 5 (2017), pp. 91-126. DOI: https://doi.org/10.24215/25251678e089

Fuentes Contreras, Édgar Hernán, Legislación en sentido material, Bogotá D.C., Grupo Editorial Ibáñez, 2018.

Fuentes Contreras, Édgar Hernán, Materialidad de la Constitución, Bogotá D.C., Grupo Editorial Ibáñez, 2010.

Fuentes Contreras, Édgar Hernán y Luz Eliyer Cárdenas Contreras, “Genealogía de la asimilación de lo normativo: análisis del estudio del Derecho en los inicios de las universidades occidentales", en Razón Crítica 3 (2017), pp. 85-110. DOI: https://doi.org/10.21789/25007807.1236

Fuentes Contreras, Édgar Hernán, Beatriz Eugenia Suárez López y Adriana Rincón Villegas, "Facticidad y acción de tutela: presentación preliminar de un estudio empírico de la formulación y efectos de la acción de tutela en el marco colombiano, entre los años 1992-2011", en Civilizar 14 (27) (2014), pp. 41-64. DOI: https://doi.org/10.22518/16578953.178

García Belaúnde, Domingo, "La interpretación constitucional como problema", en Estudios Políticos (Nueva Época) 86 (1994), pp. 9-37.

García Jaramillo, Leonardo, “De la 'constitucionalización' a la 'convencionalización' del ordenamiento jurídico. La contribución del ius constitutionale commune", en Revista Derecho del Estado 36 (2016), pp. 131-166. DOI: https:// doi.org/10.18601/01229893.n36.05

366 García Jaramillo, Leonardo, "Desafíos de la interamericanización del Derecho: la contribución del Ius Constitutionale Commune", en Revista de 
Derecho Político 1 (97) (2016), pp. 337-368. DOI: https://doi.org/10.5944/ rdp.97.2016.17627

Gascón Abellán, Marina, La interpretación constitucional/Constitución de la República de El Salvador 1983/Ley de procedimientos constitucionales, San Salvador, Consejo Nacional de la Judicatura, 2013.

Goig Martínez, Juan Manuel, “La interpretación constitucional y las sentencias del Tribunal Constitucional. De la interpretación evolutiva a la mutación constitucional", en Revista de Derecho UNED 12 (2013), pp. 257-292. DOI: https://doi.org/10.5944/rduned.12.2013.11696

González Vicen, Felipe, "Rudolf von Ihering y el problema del método jurídico", en Anuario de filosofía del derecho 4 (1987), pp. 223-248.

Häberle, Peter, "Métodos y principios de interpretación constitucional. Un catálogo de problemas", en Revista de Derecho Constitucional Europeo 13 (2010), pp. 379-414.

Hakansson Nieto, Carlos, "El efecto ondulatorio de las fuentes en un Estado Constitucional de Derecho", en THEMIS 67 (2015), pp. 39-48. http://revistas.pucp.edu.pe/index.php/themis/article/view/14455.

Hakansson Nieto, Carlos, "Los principios de interpretación y precedentes vinculantes en la jurisprudencia del Tribunal Constitucional peruano. Una aproximación", en Díkaion 18 (2009), pp. 55-77. https://dikaion.unisabana. edu.co/index.php/dikaion/article/view/1543.

Halpérin, Jean-Louis, “Exégesis (escuela)", en Revista de Derecho 48 (2017), pp. 263-277. DOI: https://doi.org/10.14482/dere.48.10148

Hespanha, António Manuel, “Tomando la historia en serio. Los exégetas según ellos mismos", en FORUM 3 (2012), pp. 13-51.

Kelsen, Hans, ¿Quién debe ser el defensor de la Constitución?, 2 ed., Madrid, Tecnos, 1999.

Kelsen, Hans, Teoría General del Derecho y del Estado, México D.F., UNAM, trad. Eduardo García Máynez, 1995.

Laise, Luciano D., "La distinción entre interpretación y construcción: una visión crítica del originalismo del significado público", en Ius et Praxis 25 (3) (2019), pp. 249-276. DOI: https://doi.org/10.4067/S0718-00122019000300249

Laporta, Francisco J., “Materiales para una reflexión sobre racionalidad y crisis de la ley", en Doxa 22 (1999), pp. 321-330. DOI: https://doi.org/10.14198/ DOXA1999.22.14 
Martínez Estay, José Ignacio, “El juez y los efectos de la Constitución en el tiempo", en Estudios Constitucionales 1 (1) (2003), pp. 715-737.

Martínez Estay, José Ignacio, “Los conceptos jurídicos indeterminados en el lenguaje constitucional", en Revista de Derecho Político 105 (2019), pp. 161196. DOI: https://doi.org/10.5944/rdp.105.2019.25272

Martínez Estay, José Ignacio, Constitución, conceptos indeterminados y conceptos controvertidos, Valencia, Tirant lo Blanch, 2021.

Massé Narváez, Carlos E. y Juan Rivera Hernández, “La hermenéutica en la interpretación conforme de los derechos humanos en el orden jurídico mexicano", en Methaodos 2 (1) (2014), pp. 36-44.

Moncada Zapata, Juan Carlos, "Principios para la interpretación de la Constitución en la jurisprudencia de la Corte Constitucional colombiana", en Derecho PUCP 53 (2000), pp. 133-172. DOI: https://doi.org/10.18800/derechopucp.200001.004

Montesquieu, Charles-Louis de Secondat, El Espíritu de las Leyes, Tomo I, Madrid, Librería General de Victoriano Suárez, trad. por Siro García Del Mazo, 1906.

Olano García, Hernán Alejandro, "La cosa juzgada en Colombia”, en Revista Jurídica UCES 11 (2007), pp. 85-95.

Olano García, Hernán Alejandro, “Tipología de nuestras sentencias constitucionales", en Vniversitas 108 (2004), pp. 571-602.

Parada Vaca, Orlando, "El Juez en el Estado Constitucional”, en Revista Boliviana de Derecho 13 (2012), pp. 7-9.

Pereira Menaut, Antonio Carlos, “Un concepto d'orsiano de Constitución: en memoria de Álvaro d'Ors", en Razón Española 137 (2007), pp. 303-320.

Pereira Menaut, Antonio Carlos, “Un concepto orsiano de Constitución”, en Revista de Derecho 2 (26) (2005), pp. 315-326.

Pereira Menaut, Antonio Carlos, Lecciones de Teoría Constitucional y otros escritos, Santiago de Compostela, Andavira, 2016.

Picado Vargas, Carlos Adolfo, “Los valores y la interpretación material, sistemática y evolutiva de la Constitución y los Derechos Humanos a la luz del tridimensionalismo jurídico", en Justicia 25 (2014), pp. 124-150. DOI: https://doi.org/10.17081/just.19.25.662

368 Quiroga León, Aníbal, “La interpretación constitucional”, en Derecho PUCP 39 (1985), pp. 323-343. DOI: https://doi.org/10.18800/derechopucp.198501.010 
Risso Ferrand, Martín, "Mutación e interpretación evolutiva de la Constitución", en Estudios Constitucionales 1 (2017), pp. 217-254. DOI: https://doi. org/10.4067/S0718-52002017000100008

Robles, Gregorio, "El derecho como text. En torno a la fundamentación de una Teoría Comunicacional del Derecho", en Persona y Derecho 35 (1996), pp. 195-226.

Robles, Gregorio, Teoría del derecho: fundamentos de Teoría Comunicacional del Derecho, Navarra, Civitas, Thomson Reuters, Aranzadi, 2015.

Rodríguez, Gabriela, Alberto Puppo, Raymundo Gama y Jorge Cerdio, Interpretación conforme, México D.F, SCJN, OACNUDH y CDHDF, 2013.

Romboli, Roberto, “La interpretación de la ley a la luz de la Constitución. La llamada 'interpretación conforme' en las relaciones entre la Corte Costituzionale y los jueces ordinarios en Italia", en Derecho PUCP 60 (2007), pp. 123-169.

Savigny, Friedrich Karl von, Sistema de Derecho Romano Actual, 2 ed., Madrid, Centro Editorial de Góngora, 1873.

Sterling Casas, Juan Pablo y Pedro María Osma, “La hermenéutica en la Teoría Comunicacional del Derecho: la teoría de textos", en Filosofía UIS 17 (1) (2018), pp. 243-269. DOI: https://doi.org/10.18273/revfil.v17n1-2018012

Terol Becerra, Manuel José, "Sobre la interpretación de la Constitución y de la Ley en España (1812-1978)", en Revista del Centro de Estudios Constitucionales 15 (1993), pp. 183-235.

Velluzzi, Vito, “Interpretación sistemática: ¿un concepto realmente útil? Consideraciones acerca del sistema jurídico como factor de interpretación", en Doxa I (21) (1998), pp. 65-82. DOI: https://doi.org/10.14198/ DOXA1998.21.1.04

Vigo, Rodolfo L., La interpretación (argumentación) jurídica en el Estado de Derecho Constitucional, Ciudad de México, Tirant Lo Blanch, 2017.

\section{Jurisprudencia constitucional citada}

Corte Constitucional, Sentencia T-422 del 19 de junio de 1992, M. P. Eduardo Cifuentes Muñoz.

Corte Constitucional, Sentencia T-406 del 5 de junio de 1992, M. P. Ciro Angarita Barón.

Corte Constitucional, Sentencia C-011 del 21 de enero de 1994, M. P. Alejandro Martínez Caballero. 
Corte Constitucional, Sentencia C-222 del 5 de mayo de 1994, M. P. Antonio Barrera Carbonell.

Corte Constitucional, Sentencia C-265 del 2 de junio de 1994, M. P. Alejandro Martínez Caballero.

Corte Constitucional, Sentencia T-397 del 20 de agosto de 1997, M. P. Antonio Barrera Carbonell.

Corte Constitucional, Sentencia C-400 del 10 de agosto de 1998, M. P. Alejandro Martínez Caballero.

Corte Constitucional, Sentencia T-195 del 6 de abril de 1999, M. P. José Gregorio Hernández Galindo.

Corte Constitucional, Sentencia C-273 del 28 de abril de 1999, M. P. Eduardo Cifuentes Muñoz.

Corte Constitucional, Sentencia T-355 del 23 de marzo de 2000, M. P. Eduardo Cifuentes Muñoz.

Corte Constitucional, Sentencia C-1189 del 13 de septiembre de 2000, M.P. Carlos Gaviria Díaz.

Corte Constitucional, Sentencia C-649 del 20 de junio de 2001, M. P. Eduardo Montealegre Lynett.

Corte Constitucional, Sentencia C-774 del 25 de julio 2001, M. P. Rodrigo Escobar Gil.

Corte Constitucional, Sentencia C-836 del 9 de agosto de 2001, M. P. Rodrigo Escobar Gil.

Corte Constitucional, Sentencia C-867 del 15 de agosto de 2001, M. P. Manuel José Cepeda Espinosa.

Corte Constitucional, Sentencia T-982 del 13 de septiembre de 2001, M. P. Manuel José Cepeda Espinosa.

Corte Constitucional, Sentencia C-955 del 6 de septiembre de 2001, M. P. Marco Gerardo Monroy Cabra.

Corte Constitucional, Sentencia C-1026 del 26 de septiembre de 2001, M. P. Eduardo Montealegre Lynett.

Corte Constitucional, Sentencia T-1031 del 27 de septiembre de 2001, M. P. Eduardo Montealegre Lynett.

370 Corte Constitucional, Sentencia C-251 del 11 de abril de 2002, M. P. Eduardo Montealegre Lynett y Clara Inés Vargas Hernández. 
Corte Constitucional, Sentencia C-426 del 29 de mayo de 2002, M. P. Rodrigo Escobar Gil.

Corte Constitucional, Sentencia C-758 del 17 de septiembre de 2002, M. P. Álvaro Tafur Galvis.

Corte Constitucional, Sentencia T-248 del 21 de marzo de 2003, M. P. Eduardo Montealegre Lynett.

Corte Constitucional, Sentencia T-334 del 30 de abril de 2003, M. P. Manuel José Cepeda Espinosa.

Corte Constitucional, Sentencia T-468 del 5 de junio de 2003, M. P. Rodrigo Escobar Gil.

Corte Constitucional, Sentencia T-907 del 17 de septiembre de 2004, M. P. Manuel José Cepeda Espinosa.

Corte Constitucional, Sentencia T-055 del 21 de enero de 2005, M. P. Jaime Araújo Rentería.

Corte Constitucional, Sentencia T-216 del 10 de marzo de 2005, M. P. Humberto Antonio Sierra Porto.

Corte Constitucional. AUTO A-207 del 5 de octubre de 2005, M. P. Rodrigo Escobar Gil.

Corte Constitucional, Sentencia C-1040 del 19 de octubre de 2005, M. P. Manuel José Cepeda Espinosa, Rodrigo Escobar Gil, Marco Gerardo Monroy Cabra, Humberto Antonio Sierra Porto, Álvaro Tafur Galvis y Clara Inés Vargas Hernández.

Corte Constitucional, Sentencia C-1153 del 11 de noviembre de 2005, M. P. Marco Gerardo Monroy Cabra.

Corte Constitucional. AUTO A-272 del 13 de diciembre de 2005, M. P. Marco Gerardo Monroy Cabra.

Corte Constitucional, Sentencia C-038 del 1 de febrero de 2006, M. P. Humberto Antonio Sierra Porto.

Corte Constitucional, Sentencia C-044 del 1 de febrero de 2006, M. P. Humberto Antonio Sierra Porto.

Corte Constitucional, Sentencia C-076 del 8 de febrero de 2006, M. P. Jaime Córdoba Triviño.

Corte Constitucional, Auto A-169 del 7 de junio de 2006, M. P. Jaime Córdoba Triviño. 
Corte Constitucional, Sentencia T-613 del 13 de agosto de 2007, M. P. Rodrigo Escobar Gil.

Corte Constitucional, Sentencia T-191 del 20 de marzo de 2009, M. P. Luis Ernesto Vargas Silva.

Corte Constitucional, Sentencia T-389 del 28 de mayo de 2009, M. P. Humberto Antonio Sierra Porto.

Corte Constitucional, Sentencia C-444 del 8 de julio de 2009, M. P. Jorge Ignacio Pretelt Chaljub.

Corte Constitucional, Sentencia C-319 del 5 de mayo de 2010, M. P. Humberto Antonio Sierra Porto.

Corte Constitucional, Sentencia T-020 del 18 de enero de 2011, M. P. Humberto Antonio Sierra Porto.

Corte Constitucional, Sentencia C-878 del 22 de noviembre de 2011, M. P. Juan Carlos Henao Pérez.

Corte Constitucional, Sentencia C-305 del 25 de abril de 2012, M. P. Juan Carlos Henao Pérez.

Corte Constitucional, Sentencia SU-539 del 12 de julio de 2012, M. P. Luis Ernesto Vargas Silva.

Corte Constitucional, Sentencia C-967 del 21 de noviembre de 2012, M. P. Jorge Iván Palacio Palacio.

Corte Constitucional, Sentencia T-632 del 12 de septiembre de 2013, M. P. Luis Ernesto Vargas Silva.

Corte Constitucional, Sentencia C-103 del 11 de marzo de 2015, M. P. María Victoria Calle Correa.

Corte Constitucional, Sentencia C-054 del 10 de febrero de 2016, M. P. Luis Ernesto Vargas Silva.

Corte Constitucional, Sentencia C-666 del 30 de noviembre de 2016, M. P. Dra. Gloria Stella Ortiz Delgado.

Corte Constitucional, Sentencia C-172 del 22 de marzo de 2017, M. P. Gloria Stella Ortiz Delgado.

Corte Constitucional, Sentencia T-177 del 24 de marzo de 2017, M. P. Antonio José Lizarazo Ocampo.

372 Corte Constitucional, Sentencia C-250 del 5 de junio de 2019, M. P. José Fernando Reyes Cuartas. 